\title{
Molecular dynamics investigation of lithium borate glasses: Local structure and ion dynamics
}

\author{
Cristos-Platon E. Varsamis, Alice Vegiri, and Efstratios I. Kamitsos* \\ Theoretical and Physical Chemistry Institute, National Hellenic Research Foundation, 48 Vas. Constantinou Ave., 11635 Athens, Greece \\ (Received 19 March 2001; revised manuscript received 16 July 2001; published 14 February 2002)
}

\begin{abstract}
The effect of alkali content and temperature on the microstructure of lithium borate glasses, $x \mathrm{Li}_{2} \mathrm{O}-(1$ $-x) \mathrm{B}_{2} \mathrm{O}_{3}$, has been investigated for glass compositions $x=0.2-0.5$ and temperatures up to $1250 \mathrm{~K}$. The molecular dynamics technique has been applied, with Ewald summation and periodic boundary conditions, to a collection of ca. 256 particles confined in a primitive cubic cell and interacting through a Born-MayerHuggins-type potential augmented with three-body angular terms. The short-range order (SRO) structure was found to consist of boron-oxygen tetrahedral, $\mathrm{B}_{4}{ }^{-}[\emptyset=$ bridging oxygen atom $(\mathrm{BO})]$, and triangular units with variable number of nonbridging oxygen $(\mathrm{NBO})$ atoms, $\mathrm{B} \emptyset_{3}, \mathrm{~B} \emptyset_{2} \mathrm{O}^{-}$, and $\mathrm{B} \mathrm{O}_{2}{ }^{2-}\left(\mathrm{O}^{-}=\mathrm{NBO}\right)$. The relative abundance of SRO units was determined and found to depend on both glass composition and temperature. Increasing $\mathrm{Li}_{2} \mathrm{O}$ content at constant temperature or increasing temperature at a fixed composition was

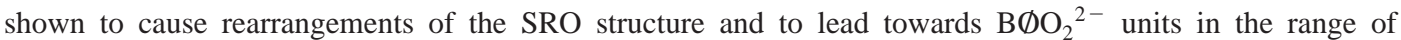
compositions and temperatures investigated. Such changes were expressed in terms of chemical equilibria involving the SRO units. The local environments hosting the $\mathrm{Li}$ ions were investigated and distinguished in two main types: the first type of site is formed by BO's, while the second type involves the participation of NBO's. The vibrational response of Li ions in the two types of site was computed and found to correlate very well with the experimental far-infrared profiles. Calculation of diffusion coefficients of Li ions showed that diffusion is carried out predominantly through NBO sites. In addition, glass regions rich in Li/NBO were found to develop with increasing lithium oxide content and to percolate eventually into microchannels suitable for ion migration.
\end{abstract}

DOI: 10.1103/PhysRevB.65.104203

PACS number(s): 61.43.Fs, 66.10.Ed

\section{INTRODUCTION}

The study of structural aspects of ionic conducting glasses and their correlation to macroscopic properties presents a fascinating challenge in the field of condensed matter physics and chemistry. ${ }^{1,2}$ Such investigations are of fundamental interest because of the potential applications of these materials as components in electrochemical devices. ${ }^{3,4}$ Thus understanding the dependence of physical properties on glass microstructure is critical for the design of materials suitable for specific applications.

Doping boron oxide with lithium oxide leads to stable ionic glasses, $x \mathrm{Li}_{2} \mathrm{O}-(1-x) \mathrm{B}_{2} \mathrm{O}_{3}$, with compositions covering a very broad and continuous range, $0 \leqslant x \leqslant 0.75 .^{5}$ The short-range order (SRO) structure of Li-borate glasses has been investigated extensively at room temperature by experimental techniques including NMR, ${ }^{6,7}$ Raman, ${ }^{8,9}$ infrared, ${ }^{10,11}$ and neutron diffraction, ${ }^{12-14}$ as well as by molecular dynamics (MD) simulations. ${ }^{15-18}$ These studies have shown that glasses with lithium oxide contents below the metaborate composition $(x=0.5)$ are characterized by a threedimensional network, the structure of which depends strongly on glass composition. In particular, increasing the alkali oxide content up to ca. $x=0.2$ results in the transformation of natural triangular borate units, $\mathrm{B} \emptyset_{3}$, into charged tetrahedral units, $\mathrm{B} \emptyset_{4}^{-}$, the formation of which contributes to the enhancement of network connectivity $[\varnothing$ denotes a bridging oxygen atom (BO), i.e., an oxygen atom bonded to two boron centers]. Further addition of lithium oxide to $\mathrm{B}_{2} \mathrm{O}_{3}$ up to ca. $x=0.5$ causes the progressive depolymerization of the glassy network through breaking of B-O-B linkages and the creation of terminal $\mathrm{B}-\mathrm{O}^{-}$bonds on charged triangular borate units, $\mathrm{B} \emptyset_{2} \mathrm{O}^{-}\left[\mathrm{O}^{-}=\right.$terminal or nonbridging oxygen atom (NBO)]. For glasses with $\mathrm{Li}_{2} \mathrm{O}$ contents exceeding $x=0.5$ the rate of network breaking increases and leads eventually to the formation of borate dimers, $\mathrm{B}_{2} \mathrm{O}_{5}{ }^{4-}$ (pyroborate), and monomers, $\mathrm{BO}_{3}{ }^{3-}$ (orthoborate), with two and three NBO's per boron center, respectively. ${ }^{10}$ Besides elucidating the structure of local boron-oxygen polyhedra, previous studies have demonstrated the arrangement of SRO structures into superstructural units with well-defined medium-range order, i.e., penta-, tri-, and di-borate groups, which are analogous to structures found in crystalline borate compounds. ${ }^{9,10,12,13}$

The effect of temperature on the structure of lithium borate glasses has not been investigated to the best of our knowledge. Nevertheless, studies on other alkali borate glasses may suggest general trends regarding the dependence of SRO structure on temperature. The statistical mechanical calculations of Araujo ${ }^{19}$ and the high-temperature NMR studies of Stebbins and co-workers ${ }^{20}$ on sodium borate glasses have shown that the fraction of $\mathrm{B}_{4}{ }^{-}$units decreases with increasing temperature. An infrared investigation of silver borate glasses ${ }^{21}$ has given evidence for structural differences between glasses having identical chemical compositions, but different thermal histories. In particular, glasses with higher fictive temperature were found to exhibit an increased fraction of $\mathrm{B} \emptyset_{2} \mathrm{O}^{-}$units relative to $\mathrm{B}_{4}{ }^{-}$tetrahedra. Similarly, high-temperature Raman spectroscopy of potassium borate glasses has shown that increasing temperature favors the formation of $\mathrm{B}_{2} \mathrm{O}^{-}$units. ${ }^{22}$ Such variations in SRO structure with temperature can be understood on the basis of the isomerization reaction 


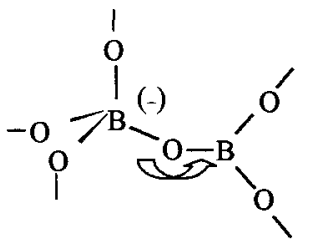

$\left[\emptyset_{3} \mathrm{~B}-\mathrm{O}-\mathrm{B}_{2}{ }^{(-)}\right]$

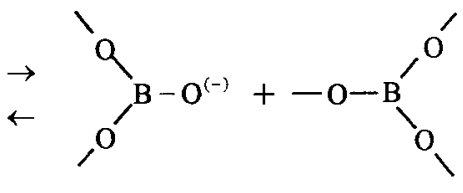

$\left[\mathrm{B} \emptyset_{2} \mathrm{O}^{(-)}+\mathrm{B} \emptyset_{3}\right]$ which leads to transformation of tetrahedral borate units into borate triangles with one NBO upon increasing temperature. $^{23}$

While the SRO borate units constitute the backbone of the glass network, at the same time they contribute to formation of sites suitable for the charge carrier metal ions. Understanding the nature of the cation-hosting environments and their distribution within the glass is an equally important aspect of glass structure. Early $\mathrm{x}$-ray scattering investigations of borate glasses containing alkali ${ }^{24}$ and thallium ${ }^{25}$ ions have suggested that the metal ions are not randomly distributed throughout the glass structure. Instead, metal ions occupy characteristic positions related to the anionic sites offered by the boron-oxygen superstructural units. This leads to the formation of metal ion pairs or larger aggregates in glasses where the closest metal-metal distance was found to be very similar to that in corresponding crystalline compounds. Recent NMR studies of sodium-borate glasses suggest a rather homogeneous distribution of metal ions, except for glasses with sodium oxide content below ca. 16 mol \%. ${ }^{26}$ Farinfrared spectroscopy of Li-borate glasses revealed the existence of at least two distinct distributions of cation-hosting sites, ${ }^{10,11}$ and this was found to present a general characteristic of alkali borate glasses. ${ }^{27}$ This so-called "two-site" model was attributed to the chemical versatility of borate networks to provide sites for metal ions with variable charge density and coordination number. ${ }^{28}$ In a different approach, the entire absorption in the far-infrared region of sodiumborate glasses was attributed to vibrational modes of sodium ions in a single type of sodium ion site. ${ }^{29}$ However, Wright and co-workers ${ }^{30}$ argued that the rigidity of the borate superstructural units and the lack of periodicity in glass should lead naturally to a considerable variation of sites in terms of both site distortion and coordination number of the metal ion.

It is evident from the above that the microstructure of the metal-ion-site arrangements in glasses and their spatial distribution remain a matter of open discussion. And yet good knowledge of the complex environments of metal ions in glass is important for understanding the composition dependence of physical properties like ionic transport and optical basicity. For example, several theoretical approaches of the ion transport mechanism in glasses assume the existence of distinct metal ion sites and propose preferred pathways for ion transport, ${ }^{31}$ cation microsegregation in channels suitable for ion migration, ${ }^{32}$ or cation-site memory effects related to transport properties. ${ }^{33}$ Recently, conductivity mechanisms based on the "two-site" model for metal ions have been proposed for single ${ }^{34-36}$ and mixed alkali ${ }^{37}$ glasses. In addition to these theoretical aspects, it was shown that close correlations could be established between the metal-ion-site vibration frequencies in the far-infrared and glass properties like basicity ${ }^{38}$ and activation energy for ion transport. ${ }^{39}$

In this paper we present results of a molecular dynamics study of lithium borate glasses at different compositions and temperatures, aiming at elucidating the microstructure of the local environments of lithium ions and aspects of the lithium ion dynamics. All MD simulations were carried out by adopting a potential employed in previous studies of Verhoef and den Hartog ${ }^{17}$ on the same system. First, we focus on the effect of temperature and composition on the short-range order structure of glass and discuss the MD results in comparison with experimental NMR and infrared findings. Then we use the structural information obtained from the simulations to explore the nature of sites hosting Li cations. We find that it is possible to distinguish $\mathrm{Li}$ cations according to the particular environment in which they predominantly reside and calculate the Li-ion-site vibrational properties in the far infrared. The calculated far-infrared responses are compared with experimental spectra and are shown to provide a microscopic origin of the "two-site" model for alkali borate glasses. Lithium ions in different anionic environments were found to exhibit differences in their long-time motions, and this is manifested in the corresponding diffusion coefficients calculated form mean square displacement data. The results are discussed in relation with the nature of the short-range order structures constituting the sites of lithium ions in borate glasses.

\section{COMPUTATIONAL PROCEDURE}

Four glass compositions were investigated in the $x \mathrm{Li}_{2} \mathrm{O}-(1-x) \mathrm{B}_{2} \mathrm{O}_{3}$ system $(x=0.2,0.3,0.4$, and 0.5$)$ by the molecular dynamics technique at temperatures $T=300,600$, and $1250 \mathrm{~K}$. In all simulations, structures consisting of ca. 256 atoms in a primitive cubic cell have been generated. The number of atoms used in each composition and the lattice constant of the unit cell, as determined from experimental density data, ${ }^{40,41}$ are summarized in Table I.

Interatomic interactions were treated by means of the usual Born-Mayer-Huggins potential ${ }^{17}$

$$
V_{i j}(r)=A_{i j} \exp (-r / \rho)+z_{i} z_{j} e^{2} / r,
$$

where

$$
A_{i j}=20.3545\left(1+\frac{z_{i}}{\eta_{i}}+\frac{z_{j}}{\eta_{j}}\right) \exp \left(\frac{r_{i}+r_{j}}{\rho}\right) \quad(\mathrm{kJ} / \mathrm{mol}) .
$$

In Eqs. (2) and (3), $z_{i} e, \eta_{i}$, and $r_{i}$, are the charge, number of valence shell electrons, and ionic radius of ion $i$, and $\rho$ is the repulsion parameter $(\rho=0.29 \AA)$.

An additional three-body harmonic interaction potential term for the O-B-O angles was included:

$$
V_{i j k}=0.5 K_{i j k}\left(\theta-\theta_{0}\right)^{2},
$$

where $K_{i j k}$ is a constant determining the strength of the interaction and $\theta$ is the angle between $i-j$ and $j-k$ bonds, where 
TABLE I. Simulation parameters for $x \mathrm{Li}_{2} \mathrm{O} \cdot(1-x) \mathrm{B}_{2} \mathrm{O}_{3}$ glasses.

\begin{tabular}{cccccccc}
\hline \hline \multirow{2}{*}{$\begin{array}{c}\text { Glass } \\
\text { composition } \\
x\end{array}$} & \multicolumn{3}{c}{ Number of atoms } & & \multicolumn{3}{c}{$R_{\text {box }}(\AA)$} \\
\cline { 2 - 3 } & $\mathrm{B}$ & $\mathrm{O}$ & $\mathrm{Li}$ & & $T=300 \mathrm{~K}$ & $T=600 \mathrm{~K}$ & $T=1200 \mathrm{~K}$ \\
\hline 0.2 & 89 & 144 & 21 & & 13.84 & 13.92 & 14.37 \\
0.3 & 81 & 139 & 35 & & 13.54 & 13.58 & 14.09 \\
0.4 & 73 & 134 & 49 & & 13.36 & 13.55 & 14.08 \\
0.5 & 64 & 128 & 64 & & 13.33 & 13.47 & 14.05 \\
\hline \hline
\end{tabular}

$i$ and $k$ are the oxygen atoms bonded to the $j$ th boron atom. The angle $\theta_{0}$ corresponds to the expected angle value for ideal triangular and tetrahedral local borate units of the network. Like $\theta_{0}$, the $K_{i j k}$ constant assumes different values when it refers to tetrahedral and triangular boron-oxygen units. The values of parameters which appear in Eqs. (2)-(4) are the same as those of Ref. 17, where a partial screening of the electrostatic charges necessary for the reproduction of experimental infrared and Raman spectra was adopted.

Our simulations have been carried out at the microcanonical ensemble, where the initial configuration resulted from a random distribution of atoms over the sites of an fcc cubic lattice, with velocities taken from a Maxwellian distribution at $6000 \mathrm{~K}$. Periodic boundary conditions were applied, and long-range Coulombic forces were handled by employing the Ewald summation method. ${ }^{42}$ A fifth-order Gear predictorcorrector integrator with a time step of $0.96 \mathrm{fs}$ was used. The generated melts were quenched to the final temperature in five cooling cycles. Each cycle consisted of a fast cooling step for about $2 \mathrm{ps}$ and an equilibration period of about 10 ps. During the first four cooling cycles, the structure of the system was driven by potential $V_{i j}$ alone, Eq. (2). At the fourth cycle the structure was evaluated to identify boron atoms in threefold and fourfold coordination. This was done at every time step by counting the number of oxygen atoms in the vicinity of each boron atom within a cutoff distance that corresponds to the first minimum in the B-O partial distribution function, which was evaluated in a preceding short run. The three-body O-B-O terms of the potential $V_{i j k}$ are switched on at the end of the fourth cooling cycle with the set of parameters depending on boron coordination. The equilibration period in the final cooling cycle was $30 \mathrm{ps}$, and properties were accumulated for a final period of about 60 ps.

\section{RESULTS AND DISCUSSION}

\section{A. Structure of simulated glasses}

\section{Effect of temperature and composition on the short-range order structure}

In order to determine the nature of the local boron-oxygen polyhedra of the glassy network we have examined the B-O radial distribution functions (RDF's) at each glass composition and temperature investigated here. It was found that the present results at room temperature are in close agreement with experimental neutron scattering data ${ }^{13,14}$ and previous MD simulations. ${ }^{17}$ From the B-O pair distribution functions the average boron coordination numbers with oxygen, $\langle\mathrm{B}(\mathrm{O})\rangle$, have been calculated and employed to determine the molar fraction of the network building SRO borate units. For doing so we examine first the O-B-O angle distribution functions, and Fig. 1 shows a typical example for the composition $x=0.3$ and temperature $T=300 \mathrm{~K}$. It is found that the $\mathrm{O}-\mathrm{B}-\mathrm{O}$ angle distribution functions are characterized by the appearance of two well-defined peaks at ca. $109.5^{\circ}$ and $120^{\circ}$, which are attributed to regular tetrahedral and planar triangular borate units, respectively. In addition, it was found that the O-B-O angle distribution functions peak always at $109.5^{\circ}$ and $120^{\circ}$ regardless of temperature and composition, indicating that the tetrahedral and planar triangular boron-oxygen units are the only network building blocks for the compositions and temperatures investigated in this work.

On the basis of these results we can now determine the molar fraction $X_{4}$ of $\mathrm{B}_{4}{ }^{-}$tetrahedral from the simple expression $X_{4}=\langle\mathrm{B}(\mathrm{O})\rangle-3$. The composition and temperature dependence of $X_{4}$ for Li-borate glasses is illustrated in Fig. 2. Room-temperature NMR data ${ }^{6,7}$ are depicted for comparison and show a good agreement with the simulated values at $T=300 \mathrm{~K}$. It is noted that the present $X_{4}$ values at room

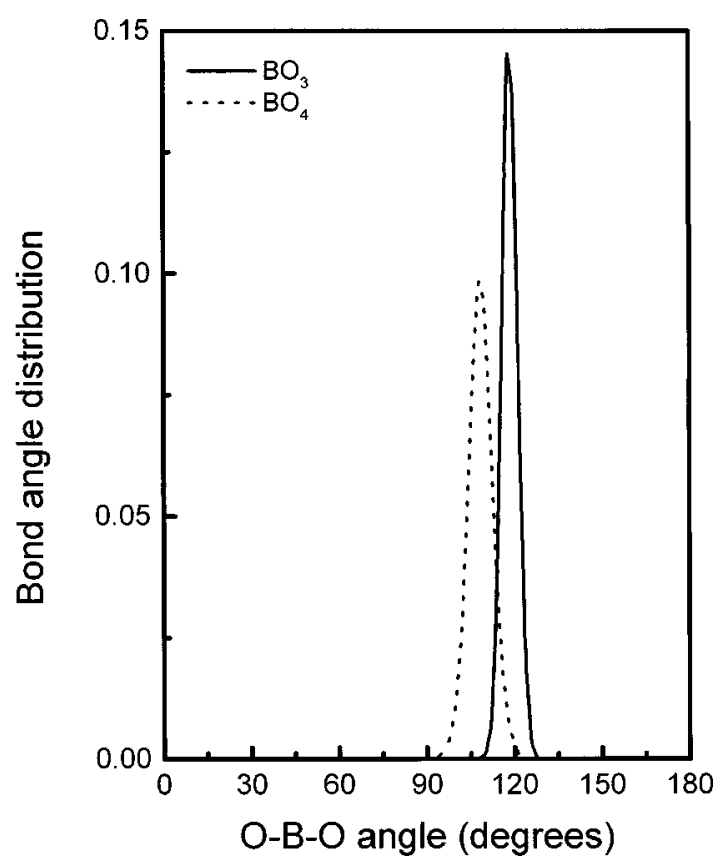

FIG. 1. Distribution of bond angle OB̂O manifesting the presence of planar triangular and tetrahedral boron-oxygen units for glass $0.3 \mathrm{Li}_{2} \mathrm{O}-0.7 \mathrm{~B}_{2} \mathrm{O}_{3}$ and temperature $T=1250 \mathrm{~K}$. 


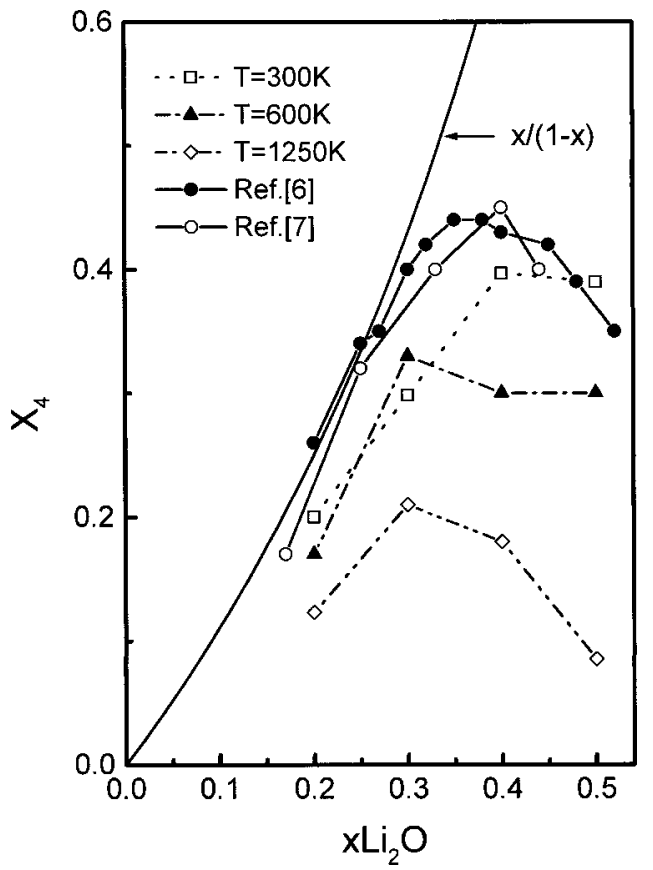

FIG. 2. Mole fraction $X_{4}$ of tetrahedral $\mathrm{B}_{4}{ }^{-}$units as a function of composition and temperature for $x \mathrm{Li}_{2} \mathrm{O}-(1-x) \mathrm{B}_{2} \mathrm{O}_{3}$ glasses $(\emptyset=$ bridging oxygen atom). Comparison is made with experimental NMR data at room temperature (Refs. 6 and 7) and the theoretical curve $x /(1-x)$ that is obtained when 1 mol of added $\mathrm{Li}_{2} \mathrm{O}$ converts $2 \mathrm{~mol}$ of $\mathrm{B} \emptyset_{3}$ triangular units into $2 \mathrm{~mol}$ of $\mathrm{B}_{4}{ }^{-}$tetrahedral.

temperature are systematically larger than those found in earlier simulations by Verhoef and den Hartog ${ }^{17}$ even though we adopted the same potential. Such differences can be attributed to two different factors: first, to the higher cooling rate employed in Ref. 17 than the one used in the current simulations, i.e., from 6000 to $300 \mathrm{~K}$ in 22.5 ps in Ref. 17 and 80 ps in this study. As discussed in previous studies, ${ }^{17,18}$ high cooling rates of simulated glasses yield larger fractions of NBO-containing units and, consequently, smaller fractions of $\mathrm{B} \emptyset_{4}{ }^{-}$units. The second factor concerns the different temperatures at which the three-body potential terms were switched on to stabilize the tetrahedral and triangular borate units. While in Ref. 17 this was done at $900 \mathrm{~K}$, in the present study the three-body terms were included at a lower temperature, $750 \mathrm{~K}$. This fact, combined with the conversion of $\mathrm{B} \emptyset_{4}{ }^{-}$units into NBO-containing units with increasing temperature suggests that in this study the three-body terms were applied to a simulated structure having already a higher fraction of $\mathrm{B}_{4}{ }^{-}$units as compared to the one of Ref. 17. We note also that the recent simulations of Cormack and Park ${ }^{18}$ give smaller $X_{4}$ values compared to our room-temperature results, but such differences can arise from the different potential models employed in the two studies.

As the temperature increases, the MD results show a systematic decrease of fraction $X_{4}$. Since the deviation of $X_{4}$ for the theoretical value $x /(1-x)$ signifies the presence of triangular borate units with NBO's, Fig. 2 shows that a gradual transformation of $\mathrm{B}_{4}{ }^{-}$units into charged triangular units takes place at each composition with increasing tem-

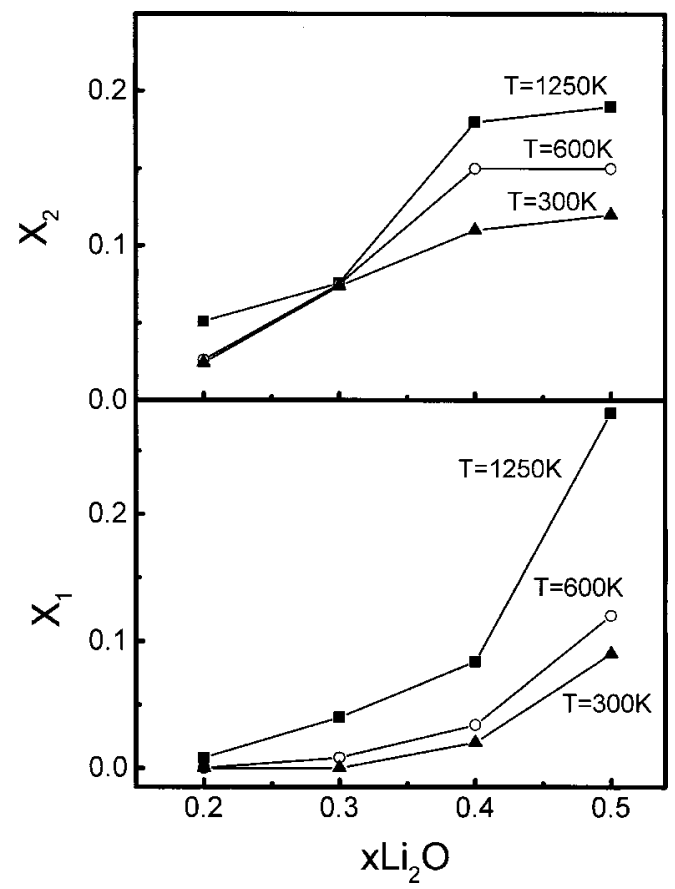

FIG. 3. Mole fractions of triangular borate units $\mathrm{B}_{2} \mathrm{O}^{-}, X_{2}$, and $\mathrm{B} \emptyset \mathrm{O}_{2}{ }^{2-}, X_{1}$, as a function of composition and temperature for $x \mathrm{Li}_{2} \mathrm{O}-(1-x) \mathrm{B}_{2} \mathrm{O}_{3}$ glasses.

perature. Whether these triangular borate units have one or two NBO atoms is examined further. An oxygen atom is designated as nonbridging if no other boron atom is found within a sphere of ca. 2 A radius. This distance corresponds to the first minimum of the B-O RDF curves, and it was found to be independent of temperature and composition. This procedure allows for the determination of the total number of NBO atoms, $N$. If $N_{2}$ and $N_{1}$ denote the number of triangular borate units with one and two NBO's respectively, and since NBO's are not formed on tetrahedral borate units for the range of compositions investigated, then

$$
N_{2}+2 N_{1}=N
$$

From charge balance considerations we may write

$$
\left(N_{2}+2 N_{1}\right) /\left(N_{1}+N_{2}\right)=\langle q\rangle,
$$

where $\langle q\rangle$ is the average charge per triangular borate unit, i.e., the average number of NBO's bonded to a threefoldcoordinated boron atom, with the limiting values of $\langle q\rangle$ being 1 for $\mathrm{B} \emptyset_{2} \mathrm{O}^{-}$and 2 for $\mathrm{B} \emptyset \mathrm{O}_{2}{ }^{2-}$. The average charge $\langle q\rangle$ $=1+\langle p\rangle$, where $\langle p\rangle$ is calculated from the integration of the first narrow peak of the corresponding NBO-NBO correlation functions, which will be presented later on, and is associated to the average number of NBO's seen by an NBO atom on the same triangular unit.

From Eqs. (5) and (6), $N_{1}$ and $N_{2}$ are obtained and this leads to evaluation of the molar fractions $X_{1}$ and $X_{2}$ of units ${\mathrm{B} \emptyset O_{2}}^{2-}$ and $\mathrm{B}_{2} \mathrm{O}^{-}$, respectively. The results are presented in Fig. 3 and show that the doubly charged triangular units, $\mathrm{B} \mathrm{O}_{2}{ }^{2-}$, do not appear at appreciable amounts for compositions $x=0.2$ and 0.3 and temperatures $T=300$ and $600 \mathrm{~K}$, in very good agreement with earlier studies by NMR (Refs. 6 
and 7) and vibrational spectroscopy. ${ }^{8-11}$ Increasing temperature in this composition range results in the decrease of $X_{4}$ (Fig. 2) and the parallel increase of $X_{2}$ (Fig. 3), in accordance with the transformation of $\mathrm{B}_{4}{ }^{-}$tetrahedra into mainly $\mathrm{B}_{2} \mathrm{O}^{-}$units expressed by Eq. (1). However, at higher $\mathrm{Li}_{2} \mathrm{O}$ contents $(x=0.4$ and 0.5$)$ and temperatures $(T$ $=1250 \mathrm{~K})$ the decrease of the $\mathrm{B} \emptyset_{4}{ }^{-}$content leads to the increase of the relative population of both $\mathrm{B}_{2} \mathrm{O}^{-}$and $\mathrm{B} \emptyset \mathrm{O}_{2}{ }^{2-}$ units (Fig. 3). It is noted that the presence of $\mathrm{B} \mathrm{O}_{2}{ }^{2-}$ triangles in pyroborate dimers, $\mathrm{B}_{2} \mathrm{O}_{5}{ }^{4-}$, has been inferred from room-temperature infrared and Raman studies of Li-borate glasses with $x \geqslant 0.5 .^{8,10}$ Although in the present simulations it was difficult to identify from snapshots of the structure the presence of pyroborate moieties, structural arrangements of the form ${ }^{-} \mathrm{O} \emptyset \mathrm{B} \emptyset \mathrm{B} \emptyset \mathrm{O}^{-}$and $\emptyset_{2} \mathrm{~B} \emptyset \mathrm{BO}_{2}{ }^{2-}$ have been identified. It is of interest to note that these arrangements are chemically isomeric as expressed by the equilibrium

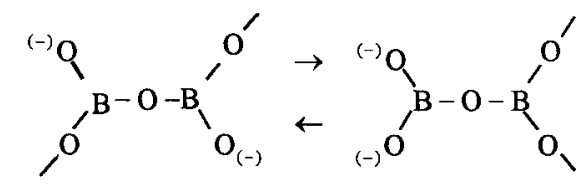

$\left[{ }^{(-)} \mathrm{O} \varnothing \mathrm{B}-\varnothing-\mathrm{B} \varnothing \mathrm{O}^{(-)}\right] \quad\left[{ }^{(-)} \mathrm{O}_{2} \mathrm{~B}-\varnothing-\mathrm{B} \emptyset_{2}\right]$

The combination of the above equilibrium and equilibrium (1) provides an explanation for the coexistence of $\mathrm{B}_{2} \mathrm{O}^{-}$ and $\mathrm{B} \emptyset \mathrm{O}_{2}{ }^{2-}$ units at high temperatures at the expense of $\mathrm{B} \emptyset_{4}^{-}$units.

Additional evidence for equilibrium (7) can be extracted from the consideration of the NBO-NBO correlation functions presented in Fig. 4 for $T=1250 \mathrm{~K}$, since at this temperature there is the largest abundance of NBO's. For comparison, the O-O RDF's from the total oxygen atom population are include in Fig. 4, where both types of correlation functions are normalized to the total number of particles in the primitive simulation cell. The NBO-NBO correlation functions display two sharp and well-defined peaks, which correspond to NBO atoms in the first shell. The first peak is at $2.25 \AA$ and can be attributed to NBO atoms belonging to the same triangular unit, like in the $\emptyset_{2} \mathrm{BOBO}_{2}{ }^{2-}$ moiety. The second peak at $3.3 \AA$ can be attributed to NBO's of connected triangular units like in the ${ }^{-} \mathrm{O} Ф \mathrm{BOB} \emptyset \mathrm{O}^{-}$species, as can be shown by simple geometric considerations. Integration of the $2.25-\AA$ peak gives the average number of NBO's seen by an NBO atom on the same triangular unit, which is the $\langle p\rangle$ value. Note that the presence of NBO's is manifested also in the total O-O correlation function in the form of a shoulder at about the same position as the second peak of the NBO-NBO correlation at $3.3 \AA$, and this shoulder gains gradually intensity with increasing lithium oxide content.

\section{Environments of Li ions}

As noted in the Introduction, the physical properties of ionic glasses depend on the nature and distribution of the

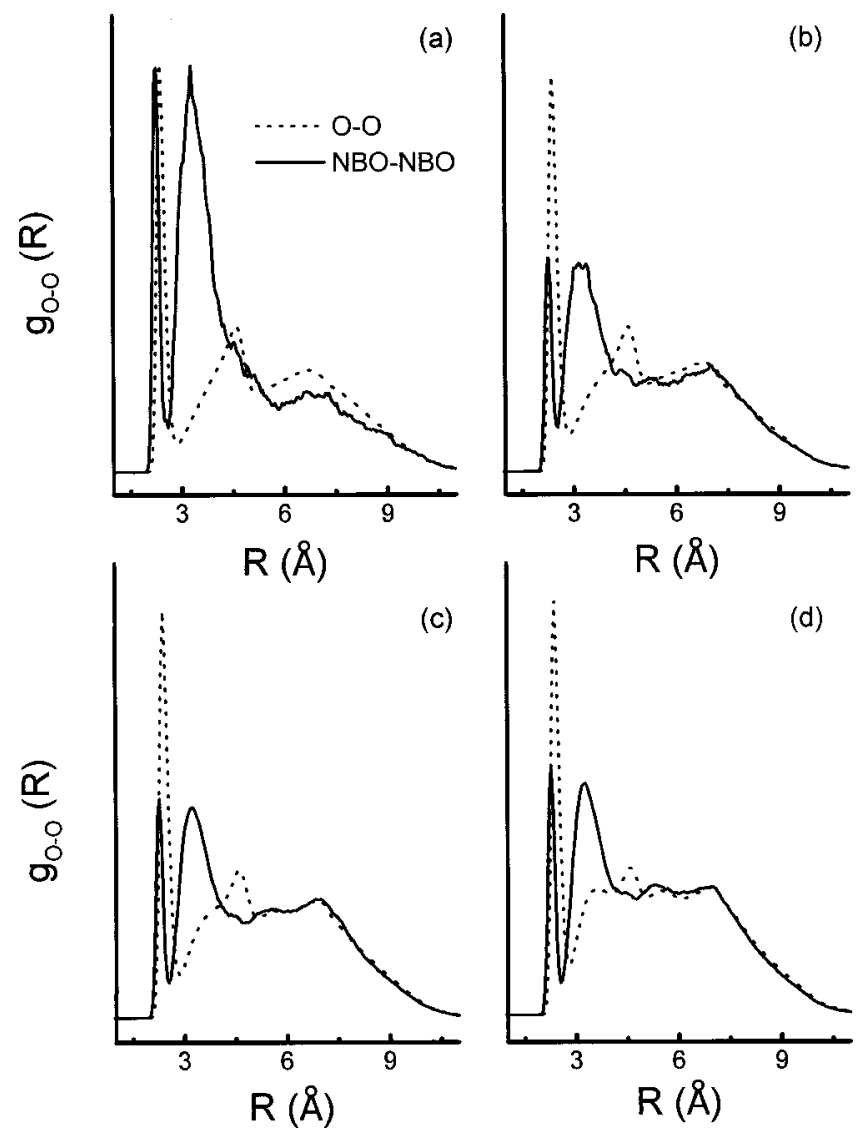

FIG. 4. O-O and NBO-NBO correlation functions at $T$ $=1250 \mathrm{~K}$ in $x \mathrm{Li}_{2} \mathrm{O}-(1-x) \mathrm{B}_{2} \mathrm{O}_{3}$ glasses: (a) $x=0.2$, (b) $x=0.3$, (c) $x=0.4$, and (d) $x=0.5$. All curves are normalized to the total number of particles in the simulation box.

cation-hosting sites. The diversity of existing viewpoints on this matter suggests that further investigations are required for elucidating the local environments of metal ions in glass. In the following, we employ the results of this MD study to reveal the microenvironments of lithium ions in borate glasses.

The SRO structures of the glass provide sites that accommodate the metal ions. In equilibrium, the positively charged $\mathrm{Li}$ ions will tend to reside in local minima of the potential energy surface associated mainly with the negatively charged SRO structural units, i.e., $\mathrm{B}_{4}{ }^{-}, \mathrm{B}_{2} \mathrm{O}^{-}$, and $\mathrm{B} \mathrm{O}_{2}{ }^{2-}$. As discussed by Wright and co-workers, ${ }^{30}$ due to the disordered nature of glass, not all of the oxygen atoms in the first coordination shell around the metal cations will be charged NBO's from $\mathrm{B}_{2} \mathrm{O}^{-}$or $\mathrm{B} \emptyset \mathrm{O}_{2}{ }^{2-}$ units or partially charged BO's from $\mathrm{B}_{4}{ }^{-}$units. It is most likely that $\mathrm{BO}$ 's from neutral $\mathrm{B} \emptyset_{3}$ units will be involved also in the formation of the coordination spheres of metal cations. Therefore, we may classify the anionic sites formed by SRO units according to the origin of oxygen atoms forming the first coordination shell of the metal ion. Sites where bridging oxygen atoms of $\mathrm{B} \emptyset_{4}{ }^{-}$and $\mathrm{B} \emptyset_{3}$ units constitute the coordination sphere of $\mathrm{Li}$ ions are designated as bridging-type ( $b$-type) sites. Anionic

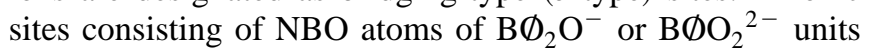
and $\mathrm{BO}$ 's of $\mathrm{B} \emptyset_{3}$ units are denoted as nonbridging-type ( $\mathrm{nb}$ - 


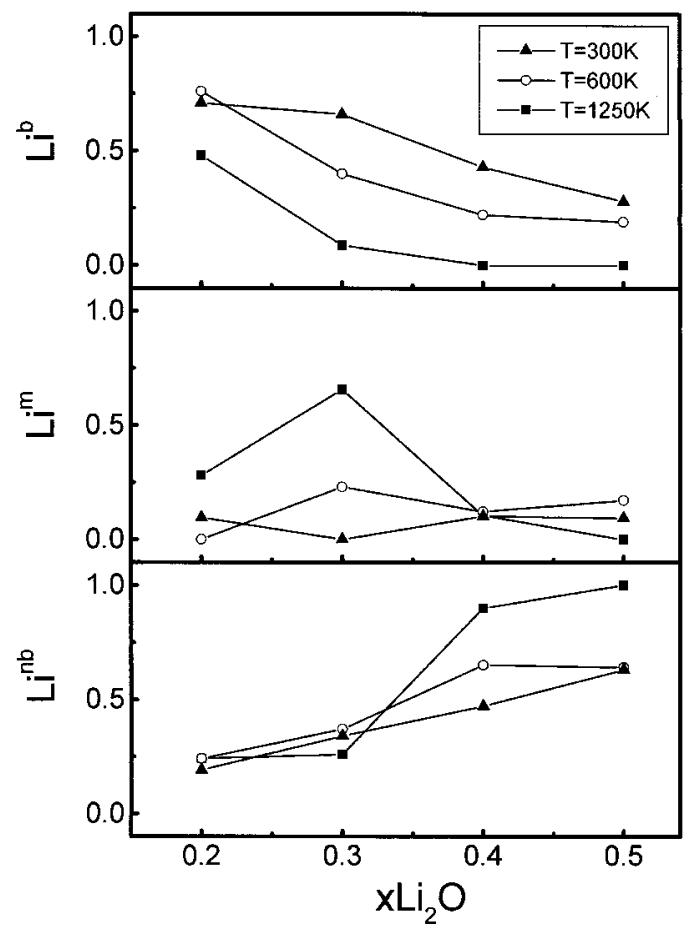

FIG. 5. Mole fractions of Li ions in $b$-type, $\mathrm{Li}^{b}, n b$-type, $\mathrm{Li}^{n b}$, and $m$-type, $\mathrm{Li}^{m}$, environments as a function of composition and temperature in $x \mathrm{Li}_{2} \mathrm{O}-(1-x) \mathrm{B}_{2} \mathrm{O}_{3}$ glasses. For details concerning the characteristics of bridging-type ( $b$-type), non-bridging-type ( $n b$ type), and mixed-type ( $m$-type) anionic sites of Li ions, see text.

type) sites, because $\mathrm{Li}$ ions in such sites tend to be located closer to NBO's than to BO's. Accordingly, a Li cation is labeled $\mathrm{Li}^{b}$ or $\mathrm{Li}^{n b}$ if it spends at least $75 \%$ of its time in a $b$-type or an $n b$-type anionic site. Li cations sharing their time between $b$-type and $n b$-type sites are labeled as mixed, $\mathrm{Li}^{m}$.

Figure 5 presents the distribution of Li ions in $b$-type, $n b$-type, and $m$-type environments as a function of temperature and composition. Inspection of this figure shows that increasing lithium oxide concentration causes an increase of the $\mathrm{Li}^{n b}$ fraction and a parallel decrease of $\mathrm{Li}^{b}$ at all temperatures. In glasses with lower $\mathrm{Li}_{2} \mathrm{O}$ contents, $x=0.2,0.3$, the decrease of the fraction $\mathrm{Li}^{b}$ at higher temperatures results mainly in the increase of the fraction $\mathrm{Li}^{m}$ rather than $\mathrm{Li}^{n b}$, as shown in Fig. 5. For compositions $x=0.4$ and 0.5 it is clear that the reduction of $\mathrm{Li}^{b}$ population at higher temperatures results in the increase of $\mathrm{Li}^{n b}$. This is consistent with the fact that the fraction of NBO-containing units was found to increase with temperature as manifested in Fig. 3. However, it was found also that the rate of increase of fraction $\mathrm{Li}^{n b}$ is greater than the rate of increase of the total number of NBO's given by Eq. (5). This result suggests that more than one $\mathrm{Li}$ cation can be coordinated to the same nonbridging oxygen atom, in agreement with MD results in sodium silicate glasses. ${ }^{43,44}$ Along the same lines, the fraction of $\mathrm{Li}^{b}$ ions is lower than the corresponding fraction of $\mathrm{B}_{4}{ }^{-}$units, $X_{4}$. Thus there is a clear preference of $\mathrm{Li}$ ions to reside in $n b$ type environments, since such anionic sites provide deeper local potential wells. To give an example, Fig. 2 shows that

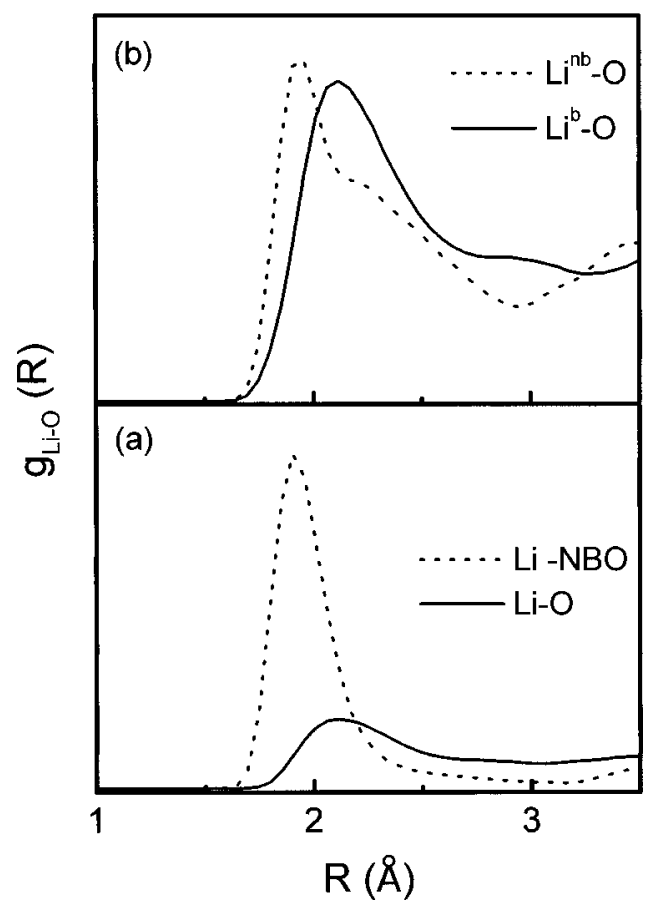

FIG. 6. Li-O pair radial distribution functions (RDF's) at $300 \mathrm{~K}$ for glass $0.3 \mathrm{Li}_{2} \mathrm{O}-0.7 \mathrm{~B}_{2} \mathrm{O}_{3}$. (a) Total $\mathrm{Li}-\mathrm{O}$ and partial $\mathrm{Li}-\mathrm{NBO}$ RDF's $(\mathrm{NBO}=$ nonbridging oxygen atom, and $\mathrm{O}=$ bridging or nonbridging oxygen atom) and (b) partial $\mathrm{Li}^{n b}-\mathrm{O}$ and $\mathrm{Li}^{b}-\mathrm{O}$ RDF's. $\mathrm{Li}$ ions are labeled $\mathrm{Li}^{b}$ and $\mathrm{Li}^{n b}$ if they are coordinated to bridgingtype and non-bridging-type anionic sites, respectively. For details see text.

for $x=0.4$ and $T=300 \mathrm{~K}$ the fraction of $\mathrm{B} \emptyset_{4}{ }^{-}$units is $X_{4}$ $=0.4$, which amounts to $75 \%$ of the total fraction of all negatively charged borate units $\left(X_{4}+X_{2}+X_{1}\right)$, but the corresponding fraction of $\mathrm{Li}^{b}$ ions is significantly lower, i.e., $43 \%$ of the total $\mathrm{Li}$ ion population. Such a trend becomes more pronounced at higher temperatures and concentrations, and this is consistent with the picture of a $\mathrm{Li}^{b}$ ion being coordinated to bridging oxygen atoms of more than one $\mathrm{B}_{4}{ }^{-}$unit as suggested by the neutron scattering study of the same system. ${ }^{14}$

Having distinguished $\mathrm{Li}$ ions according to the nature of their coordination spheres, we present in Fig. 6 the partial $\mathrm{Li}-\mathrm{O}$ radial distribution functions for composition $x=0.3$ and $T=300 \mathrm{~K}$ where Li ions are distributed mainly over $b$-type and $n b$-type sites. The total Li-O RDF results in a broad and asymmetric peak [Fig. 6(a)] and is characterized by 4.5 oxygen atoms around $\mathrm{Li}$ ions within a cutoff distance of $2.7 \AA$ and a mean Li-O distance of $2.12 \AA$, in good agreement with the results of the neutron diffraction study. ${ }^{14}$ Compared to the total Li-O RDF's the Li-NBO partial alone gives a narrow distribution around $1.92 \AA$ [Fig. 6(a)]. In Fig. 6(b) we present the Li-O RDF's that describe Li-O bonding in $n b$ type and $b$-type sites. It is seen that the partial $\mathrm{Li}^{n b}-\mathrm{O} \mathrm{RDF}$ peaks at $1.92 \AA$ and is better defined than the partial $\mathrm{Li}^{b}$-O $\mathrm{RDF}$ at $2.12 \AA$. This is reasonable since the $\mathrm{Li}^{n b}$-O RDF accounts for $\mathrm{Li}^{n b}-\mathrm{BO}$ and $\mathrm{Li}^{n b}-\mathrm{NBO}$ bonding, whereas the $\mathrm{Li}^{b}-\mathrm{O} \mathrm{RDF}$ involves only $\mathrm{Li}^{b}-\mathrm{BO}$ bonding. The coordination number $(\mathrm{CN})$ of oxygen around $\mathrm{Li}^{n b}$ is about 5.5 when a 
cutoff distance of $3.0 \AA$ is used, while $\mathrm{CN} \approx 8$ is obtained for oxygen around $\mathrm{Li}^{b}$ and a cutoff distance of $3.3 \AA$. This shows that sites hosting $\mathrm{Li}^{n b}$ ions ( $n b$ type) are better defined compared to anionic sites of $\mathrm{Li}^{b}$ ions ( $b$ type).

Close examination of the simulated structure of the $x$ $=0.3$ glass at $300 \mathrm{~K}$ reveals the coexistence of $b$-type and $n b$-type anionic sites, such as those shown in Figs. 7(a) and 7(b). The site of the Li ion in Fig. 7(a) is formed by eight nearest-neighbor oxygen atoms within a radius of $3 \AA$; four of them are bridging oxygens belonging to two $\mathrm{B}_{4}{ }^{-}$units, and the other four are bridging oxygens from $\mathrm{B}_{3}$ units. The four closer oxygens are at $\mathrm{Li}-\mathrm{O}$ distances in the range 2.1$2.3 \AA$, and the next four oxygens are at distances $2.6-3.0 \AA$. It is noted that sevenfold $\mathrm{Li}$ ion sites are formed in crystalline lithium-diborate, $\mathrm{Li}_{2} \mathrm{O}-2 \mathrm{~B}_{2} \mathrm{O}_{3}$, where $\mathrm{B}_{4}{ }^{-}$and $\mathrm{B} \emptyset_{3}$ units coexist in equal proportions. ${ }^{45} \mathrm{~A}$ typical characteristic of $b$-type sites, like the one in Fig. 7(a) is that each $\mathrm{Li}^{b}$ ion is coordinated to oxygen atoms of two $\mathrm{B}_{4}{ }^{-}$units, in agreement with results presented above and the neutron diffraction study. ${ }^{14}$

Figure 7(b) shows a segment of the structure that provides sites for three $\mathrm{Li}$ ions. The two $\mathrm{Li}$ ions at the lower part of Fig. 7(b) are in sites that involve two NBO's each and three or four BO's within a radius of $3 \AA$. Thus six- and fivefoldcoordination environments for $\mathrm{Li}$ ions are formed with average Li-O bonding distances of 2.2 and $2.3 \AA$, for these particular sites. In crystalline $\alpha$-Li-metaborate, $\mathrm{Li}_{2} \mathrm{O}-\mathrm{B}_{2} \mathrm{O}_{3}(x$ $=0.5$ ), which consists of chains of $\mathrm{B}_{2} \mathrm{O}^{-}$units, $\mathrm{Li}$ ions occupy sites formed by five oxygen atoms at an average Li-O distance of $2.07 \AA .{ }^{46}$ The site of the Li ion in the upper part of Fig. 7(b) involves one NBO and six bridging oxygen atoms, three of which are bridged to a $\mathrm{B} \emptyset_{4}{ }^{-}$unit. Therefore, it is seen in Fig. 7(b) that all three $\mathrm{Li}$ ion sites involve NBO's, and, most importantly, each NBO is coordinated to two Li ions at a distance of 1.9-2.0 $\mathrm{A}$.

The tendency of NBO's to attract more than one Li ion is exploited further through the calculation of the coordination numbers of NBO's relative to all types of $\mathrm{Li}$ ions, $\mathrm{NBO}(\mathrm{Li})$, and relative to other NBO's, NBO (NBO). We examine also the coordination numbers of $\mathrm{Li}^{n b}$ ions relative to NBO's, $\mathrm{Li}^{n b}(\mathrm{NBO})$, and to other $\mathrm{Li}^{n b}$ ions, $\mathrm{Li}^{n b}\left(\mathrm{Li}^{n b}\right)$. Coordination numbers were calculated by integration of the corresponding peaks in the radial distribution functions, such as those shown in Fig. 4 for NBO-NBO correlations. The results are presented in Table II as a function of composition and temperature. Coordination numbers $\mathrm{O}(\mathrm{O})$ and $\mathrm{Li}(\mathrm{O})$ were also obtained in this study and were found to be in close agreement with those reported in the literature. ${ }^{13,17}$ As seen in Table II, the average number of $\mathrm{Li}$ ions in the neighborhood of an $\mathrm{NBO}, \mathrm{NBO}(\mathrm{Li})$, varies smoothly from ca. 2 to ca. 3 with increasing $x$ and is independent of temperature. In comparison, the corresponding number of $\mathrm{Li}$ ions around an average oxygen atom, $\mathrm{O}(\mathrm{Li})$, is always smaller and varies between ca. 0.5 and 2. These findings show that, indeed, there is an increased concentration of $\mathrm{Li}$ ions at sites formed by NBO atoms, in accordance with conclusions drawn above and illustrated schematically in Fig. 7(b). Such behavior can be attributed to stronger Coulombic interactions between $\mathrm{Li}$ ions and the more polarized NBO-containing sites as com- (a)

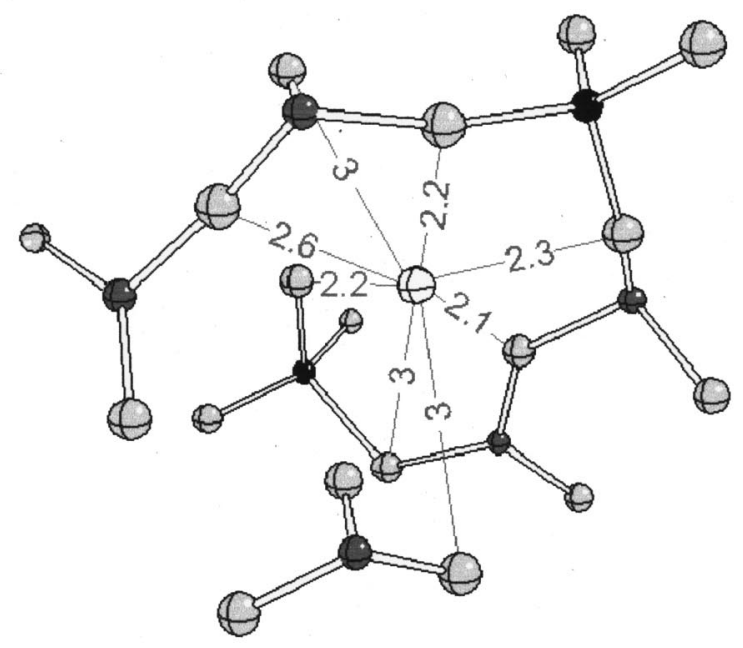

(b)

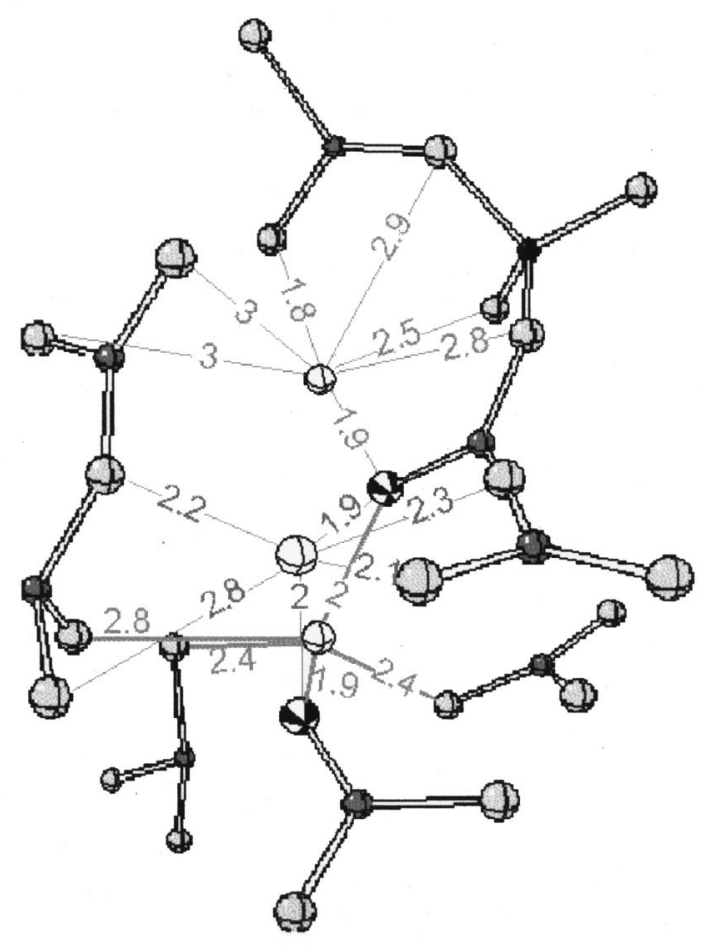

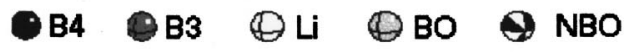

FIG. 7. Details of the simulated atomic-scale structure at $300 \mathrm{~K}$ of the $0.3 \mathrm{Li}_{2} \mathrm{O}-0.7 \mathrm{~B}_{2} \mathrm{O}_{3}$ glass revealing the presence of (a) bridging-type and (b) non-bridging-type coordination environments for $\mathrm{Li}$ ions. Distances between $\mathrm{Li}$ ions and oxygen atoms in the first coordination shell within a radius of $3 \AA$ are included. $B 4$ and $B 3$ denote four- and three-fold-coordinated boron atoms, and $\mathrm{BO}$ and $\mathrm{NBO}$ are for bridging and nonbridging oxygen atoms, respectively.

pared to sites formed by oxygen atoms of tetrahedral units. This leads to creation of deeper potential wells for Li ions associated with NBO's.

The NBO(NBO) coordination numbers in Table II are larger than unity in most cases and suggest a tendency for 
TABLE II. Coordination numbers of $\mathrm{NBO}$ and $\mathrm{O}$ atoms and $\mathrm{Li}^{\mathrm{nb}}$ cations in $x \mathrm{Li}_{2} \mathrm{O} \cdot(1-x) \mathrm{B}_{2} \mathrm{O}_{3}$ glasses as a function of composition $x$ and temperature $T$. For details see text.

\begin{tabular}{ccccccc}
\hline \hline$T(\mathrm{~K})$ & $x$ & $\mathrm{NBO}(\mathrm{Li})$ & $\mathrm{O}(\mathrm{Li})$ & $\mathrm{NBO}(\mathrm{NBO})$ & $\mathrm{Li}^{\mathrm{nb}}\left(\mathrm{Li}^{\mathrm{nb}}\right)$ & $\mathrm{Li}^{\mathrm{nb}}(\mathrm{NBO})$ \\
\hline \multirow{2}{*}{1250} & 0.2 & 2.0 & 0.6 & 1.2 & 2.5 & 1.3 \\
& 0.3 & 2.3 & 1.1 & 1.5 & 3.1 & 1.4 \\
& 0.4 & 2.6 & 1.4 & 3.0 & 4.7 & 1.8 \\
& 0.5 & 2.9 & 2.2 & 5.2 & 6.7 & 2.2 \\
600 & 0.2 & 2.2 & 0.6 & 0 & 1.3 & 1 \\
& 0.3 & 2.8 & 1.2 & 1.0 & 3.2 & 1.2 \\
& 0.4 & 3.0 & 1.8 & 2.4 & 5.4 & 1.4 \\
& 0.5 & 3.2 & 2.3 & 4.8 & 7.3 & 1 \\
300 & 0.2 & 2.4 & 0.8 & 0 & 1.9 & 1.2 \\
& 0.3 & 2.6 & 1.1 & 0.6 & 2.5 & 1.2 \\
& 0.4 & 2.8 & 1.6 & 1.5 & 3.6 & 1.4 \\
\hline \hline
\end{tabular}

NBO aggregation, which increases with lithium oxide content and temperature. This is followed by a corresponding aggregation of $\mathrm{Li}^{n b}$ ions as manifested by the $\mathrm{Li}^{n b}\left(\mathrm{Li}^{n b}\right)$ coordination numbers listed in Table II. This picture points towards the formation of cation-enriched regions in the glassy network as the metal oxide content increases, in accordance with predictions of the modified random network model of Greaves. ${ }^{32}$ The implication of this structural behavior on the transport properties of the system will be discussed further below. Aggregation of lithium ions and NBO's was also shown in MD simulations of Li-phosphate glasses, ${ }^{47,48}$ and this effect was proposed to result in lowering of the energy barriers for cation diffusion through the glassy network.

Finally, in the last column of Table II, the average number of NBO's seen by a $\mathrm{Li}^{n b}$ is presented. It is interesting to note that in all cases examined here these coordination numbers are greater than 1. Moreover, they show a progressive increase with increasing $\mathrm{Li}$ oxide content at any temperature, implying, thereby, an increase of the average negative charge density experienced by a single $\mathrm{Li}^{n b}$ cation.

Additional evidence for NBO agglomeration can be provided by a further classification of $\mathrm{Li}^{n b}$ cations according to the number of $\mathrm{NBO}$ atoms involved in $n b$-type coordination environments. Such a distinction among $\mathrm{Li}^{n b}$ cations can be based on the distribution of residence times of $\mathrm{Li}^{n b}$ ions in sites with one $\left(\mathrm{Li}^{n b 1}\right)$, two $\left(\mathrm{Li}^{n b 2}\right)$, three $\left(\mathrm{Li}^{n b 3}\right)$, or four $\left(\mathrm{Li}^{n b 4}\right)$ NBO's involved in the coordination sphere of $\mathrm{Li}^{n b}$ ions. The results at $T=1250 \mathrm{~K}$ are presented in Fig. 8 and show that, while the fraction $\mathrm{Li}^{n b 2}$ remains practically composition independent, the reduction of $\mathrm{Li}^{n b 1}$ with $x$ is followed by an increase of the fractions $\mathrm{Li}^{n b 3}$ and $\mathrm{Li}^{n b 4}$. Obviously, this is due to the fact that creation of more NBO's in glasses with higher $\mathrm{Li}_{2} \mathrm{O}$ content enhances the possibility of having more than one $\mathrm{NBO}$ in the first coordination sphere of $\mathrm{L} \mathrm{Li}^{n b}$ cation. This additional scheme of distinction among metal cations should be very useful for the identification of distinct cation-hosting sites even in glassy systems where the negative charge is located only on nonbridging oxygens. Alkali silicate glasses present such a case, and far-infrared spectroscopy reveals the existence of at least two different cation-hosting environments. ${ }^{49}$ The present results suggest that these different anionic environments in silicate glasses may differ in the number of NBO atoms in the first coordination shell of alkali cations.

\section{B. Dynamic properties of simulated glasses}

\section{Short-time dynamics: Lithium-ion-site vibrational properties}

The distinction of Li-ion-hosting sites into $b$ - and $n b$-type environments will be exploited further to establish correlations with corresponding Li-ion-site vibrations active in the far-infrared spectral range. Experimental studies of Li-borate glasses have shown that the far-infrared spectra are characterized by an asymmetric absorption profile, which gains

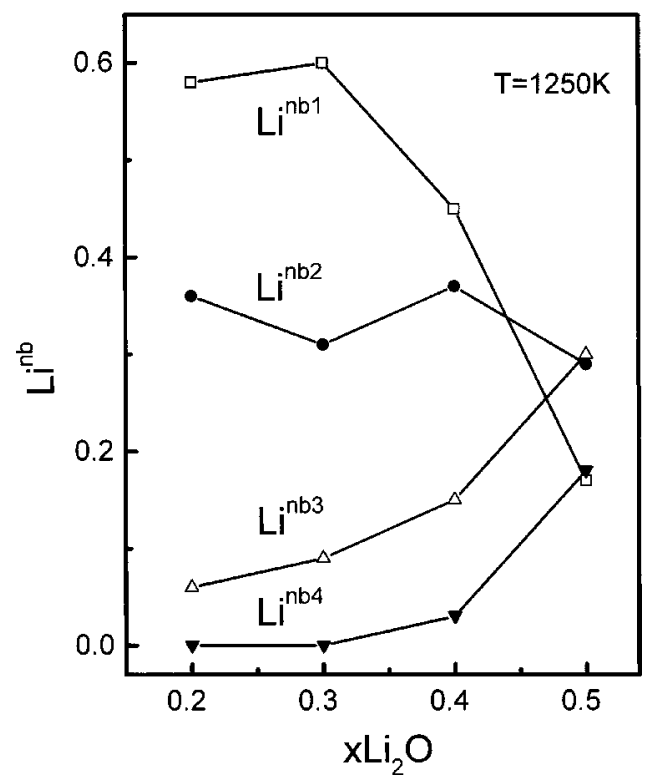

FIG. 8. Fractions of Li cations in anionic sites involving one $\left(\mathrm{Li}^{n b 1}\right)$, two $\left(\mathrm{Li}^{n b 2}\right)$, three $\left(\mathrm{Li}^{n b 3}\right)$, and four $\left(\mathrm{Li}^{n b 4}\right)$ nonbridging oxygen atoms as a function of composition in $x \mathrm{Li}_{2} \mathrm{O}-(1-x) \mathrm{B}_{2} \mathrm{O}_{3}$ glasses at $T=1250 \mathrm{~K}$. 


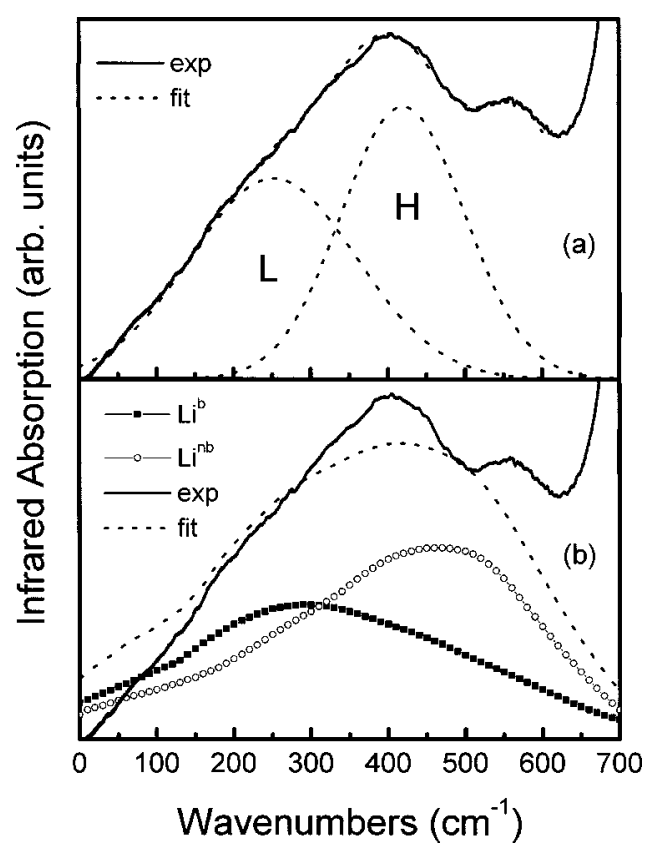

FIG. 9. (a) Experimental far-infrared spectrum of the $0.3 \mathrm{Li}_{2} \mathrm{O}-0.7 \mathrm{~B}_{2} \mathrm{O}_{3}$ glass at room temperature (solid line) and its deconvolution into Gaussian component bands $L$ and $H$ (dashed lines). (b) Calculated power spectra of $\mathrm{Li}$ ions residing in bridging-type $\left(\mathrm{Li}^{b}\right)$ and non-bridging-type $\left(\mathrm{Li}^{n b}\right)$ sites in $0.3 \mathrm{Li}_{2} \mathrm{O}-0.7 \mathrm{~B}_{2} \mathrm{O}_{3}$ glass at $300 \mathrm{~K}$. A linear combination of the two power spectra is shown for comparison with the experimental spectrum of the same glass. Note the close correspondence of bands $L$ and $H$ of the experimental spectrum with the power spectra of cations $\mathrm{Li}^{b}$ and $\mathrm{Li}^{n b}$, respectively.

relative intensity and shifts towards higher frequencies with increasing $\mathrm{Li}_{2} \mathrm{O}$ content. ${ }^{10,11}$ In addition, the far-infrared profiles were deconvoluted into two Gaussian component bands designated by $L$ for the low- and $H$ for the high-frequency band, as shown in Fig. 9 for the $0.3 \mathrm{Li}_{2} \mathrm{O}-0.7 \mathrm{~B}_{2} \mathrm{O}_{3}$ glass. ${ }^{10} \mathrm{In}$ previous studies, bands $L$ and $H$ were attributed to $\mathrm{Li}-\mathrm{O}$ vibrations in sites characterized by different coordination numbers and anionic charge density. In particular, band $H$ was associated with Li-O vibrations in sites of smaller coordination number and larger anionic charge density in comparison to Li-hosting sites, giving rise to the $L$ component band. ${ }^{10,28}$ After having distinguished in this work the anionic sites according to their microstructure, we now trace the microscopic origin of bands $L$ and $H$ by examining the vibrational characteristics of Li ions residing in $b$-type $\left(\mathrm{Li}^{b}\right)$ and $n b$-type $\left(\mathrm{Li}^{n b}\right)$ sites.

As shown in previous MD studies, ${ }^{17,50}$ the vibrational characteristics of metal ions in glass can be investigated through the velocity autocorrelation function $\Phi(t)$ :

$$
\Phi(t)=\left\langle\left(\frac{1}{N}\right) \sum_{j=1}^{N} \vec{v}_{j}(t) \cdot \vec{v}_{j}(0)\right\rangle
$$

where $\vec{v}_{j}(t)$ is the velocity of metal ion $j$ at time $t$ and $N$ is the number of metal ions. The vibrational density of states, $\Phi(\omega)$, which reflects the vibrational properties of metal ions can be obtained directly from the Fourier transform of $\Phi(t)$.
We have applied this approach separately to $\mathrm{Li}$ ions of $\mathrm{Li}^{n b}$ and $\mathrm{Li}^{b}$ type in the glass $0.3 \mathrm{Li}_{2} \mathrm{O}-0.7 \mathrm{~B}_{2} \mathrm{O}_{3}$ and calculated the corresponding $\Phi(\omega)$ spectra shown in Fig. 9(b) for $T$ $=300 \mathrm{~K}$. It is recalled that at $300 \mathrm{~K}$ and $x=0.3$, Fig. 5 shows that lithium ions are practically of $\mathrm{Li}^{b}$ and $\mathrm{Li}^{n b}$ type only.

As expected, the $\Phi(\omega)$ spectra associated with $\mathrm{Li}^{n b}$ and $\mathrm{Li}^{b}$ ions are in the far-infrared region, where both spectra are quite broad, but well separated from each other. The key finding is the fact that the spectrum of $\mathrm{Li}^{n b}$ ions appears at higher frequencies compared to that of $\mathrm{Li}^{b}$ ions and that there is a good correspondence with the experimental bands $H$ and $L$, respectively. This result is fully compatible with the nature of sites hosting lithium ions as found in this work and, in particular, the fact that $\mathrm{Li}$ ions residing in $n b$-type sites were shown to have smaller coordination numbers compared to $\mathrm{Li}^{b}$ ions. In view of this result, it is of interest to note earlier experimental findings of Tarte and co-workers from their investigation of ionic crystalline compounds. ${ }^{51-53}$ They have shown that the metal-oxygen stretching frequency in the infrared increases with decreasing coordination number of the metal cation. The present MD results are also in full agreement with earlier propositions regarding the origin of bands $H$ and $L,{ }^{10,28}$ and reveal for the first time the microstructure of anionic sites where Li-O vibrations give rise to bands designated by $H$ and $L$ in the experimental spectra. It is noted that useful information about the distribution of cations in different anionic sites and the cation-site interaction energy in glasses can be obtained also by dielectric spectroscopy, including the complex impedance and the thermally stimulated current techniques. Both techniques were applied recently to alkali borate glasses of composition $0.25 M_{2} \mathrm{O}-0.75 \mathrm{~B}_{2} \mathrm{O}_{3}(M=$ alkali $)$ and showed that the dielectric spectra are dominated by two major responses. ${ }^{54}$ It was argued that these dielectric responses could be attributed to dipolar reorientation processes in at least two types of metalion-site arrangement, and this is in accordance with the farinfrared experiments and the present MD results.

The lithium oxide content of glass was found to affect the power spectra of $\mathrm{Li}^{b}$ and $\mathrm{Li}^{n b}$ ions as shown in Fig. 10 for compositions $x=0.2$ and 0.5 and temperature $T=300 \mathrm{~K}$. It is evident that for each glass composition the calculated $\Phi(\omega)$ spectrum of $\mathrm{Li}^{n b}$ ions is at higher frequency than the spectrum of $\mathrm{Li}^{b}$ ions for reasons discussed above. In addition, the spectra of both types of Li ions exhibit a shift to higher frequency values with increasing $x$ in agreement with the experimental results. These findings suggest a gradual alteration of both $b$ - and $n b$-type sites with alkali content, and such changes may involve the coordination number and/or the average $\mathrm{Li}-\mathrm{O}$ distance.

Calculations of power spectra at high temperatures showed a tendency for $\mathrm{Li}^{b}$ - and $\mathrm{Li}^{n b}$-band merging, especially for glasses of high Li contents. This trend suggests that at high lithium contents and temperatures $\mathrm{Li}$ ions are interacting strongly with each other, and thus $\mathrm{Li}^{b}-\mathrm{O}$ and $\mathrm{Li}^{n b}-\mathrm{O}$ vibrations are getting progressively coupled. Evidence for such coupling through $\mathrm{Li}-\mathrm{Li}$ interactions is provide by the total $\mathrm{Li}(\mathrm{Li})$ coordination number. Indeed, it was found that at $T=300 \mathrm{~K}$ this coordination number is $2.6,3,5$, and 6.25 for 


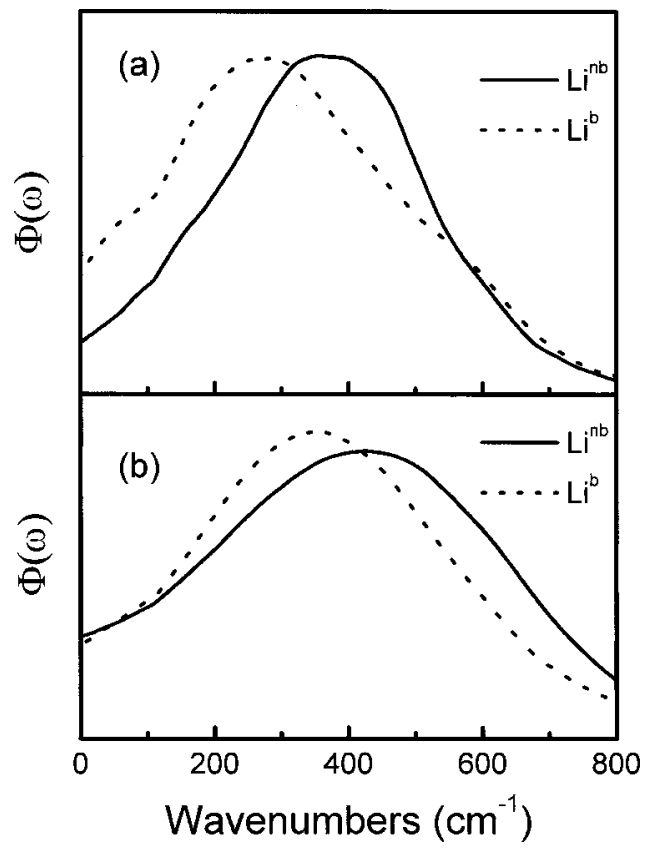

FIG. 10. Calculated power spectra $\Phi(\omega)$ at $T=300 \mathrm{~K}$ for Li ions in bridging-type $\left(\mathrm{Li}^{b}\right)$ and non-bridging-type $\left(\mathrm{Li}^{n b}\right)$ sites in $x \mathrm{Li}_{2} \mathrm{O}-(1-x) \mathrm{B}_{2} \mathrm{O}_{3}$ glasses: $x=0.2$ (a) and $x=0.5$ (b).

$x=0.2,0.3,0.4$, and 0.5 , respectively. However, at $T$ $=1250 \mathrm{~K}$ no first shell in the Li-Li RDF's was observed.

\section{Long-time dynamics: Lithium ion transport properties}

An important aspect of the dynamical properties of ionic glasses is the diffusion of metal ions. In this section we investigate the transport properties of lithium ions in borate glasses according to the local environments where they predominantly reside. The number of hops of lithium ions from site to site is very small at room temperature, and thus either a large ensemble or very large computational times are required in order to obtain results with reliable statistics. In this respect, we have examined the diffusion of $\mathrm{Li}$ cations in glass at temperatures 600 and $1250 \mathrm{~K}$.

Mean-square displacements (MSD's) of lithium cations at temperatures 600 and $1250 \mathrm{~K}$ are shown in Fig. 11 for the glass $0.3 \mathrm{Li}_{2} \mathrm{O}-0.7 \mathrm{~B}_{2} \mathrm{O}_{3}$ and include the average MSD from all lithium ions as well as the MSD's of Li ions in $n b$-and $b$-type anionic sites. It was found that the MSD's of boron and oxygen atoms at $1250 \mathrm{~K}$ have no measurable slopes, indicating that $\mathrm{Li}$ cations are the only mobile species contributing to the transport properties of glass. As observed in Fig. $11, \mathrm{Li}^{n b}$ cations are more mobile compared to $\mathrm{Li}^{b}$ cations, suggesting that the diffusion process is carried out mostly through $n b$-type anionic sites. This finding is consistent with previous model calculations ${ }^{55}$ which show that the diffusion constant of the mobile ion increases with the increase of the concentration of negative Coulombic traps in the network, due to the lowering of the intervening energy barrier. Morover, molecular dynamics studies of $\mathrm{Li}$ conduction in phosphate glasses ${ }^{50}$ have shown that Li ion migration may be associated with the presence of an optimum number of NBO's in the first coordination shell of the cations.

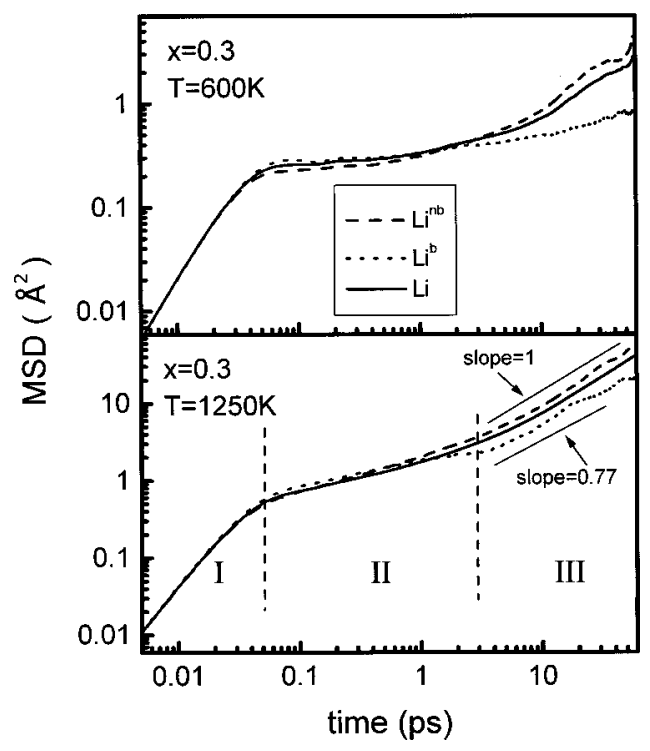

FIG. 11. Mean-square displacements of lithium ions in $0.3 \mathrm{Li}_{2} \mathrm{O}-0.7 \mathrm{~B}_{2} \mathrm{O}_{3}$ glass at temperatures 600 and $1250 \mathrm{~K}$. Li denotes the average behavior of all lithium ions, while $\mathrm{Li}^{n b}$ and $\mathrm{Li}^{b}$ indicate MSDs of lithium ions in $n b$-type and $b$-type sites, respectively.

As observed in the log-log MSD plots in Fig. 11, the three characteristic time regimes described by Funke ${ }^{56}$ i.e., the short-time (I), dispersive (II), and long-time (III) regimes, can be distinguished for $\mathrm{Li}^{n b}$ cations at both temperatures. Only for $\mathrm{Li}^{n b}$ ions and times longer than $10 \mathrm{ps}$ is the slope equal to 1, as would be expected when the macroscopic Einstein diffusion equation is applicable. The MSD curve of $\mathrm{Li}^{b}$ ions at $600 \mathrm{~K}$ shows the first two regimes only, whereas at $1250 \mathrm{~K}$ the observed change in slope at ca 3 ps does not correspond to the long-time regime (slope $=0.77$ ). If we examine the average net displacement of both types of ion at $T=1250 \mathrm{~K}$, we find that during $60 \mathrm{ps} \mathrm{Li}^{n b}$ ions have moved further (to $7.4 \AA$ ) from their original neighbors, which were located at about $3.2 \AA$ according to the corresponding $\mathrm{Li}^{n b}-\mathrm{Li}^{n b} \mathrm{RDF}$. On the contrary, $\mathrm{Li}^{b}$ ions have moved only up to a distance of $4.2 \AA$, which is smaller than the first maximum of the corresponding $\mathrm{Li}^{b}-\mathrm{Li}^{b} \mathrm{RDF}$, located at ca. $5.5 \AA$. For the particular composition $x=0.3$ we have extended the simulation time to $180 \mathrm{ps}(T=1250 \mathrm{~K})$ and find that the displacements of $\mathrm{Li}^{n b}$ and $\mathrm{Li}^{b}$ ions are 17 and $6.7 \AA$, respectively. These results show clearly that $\mathrm{Li}^{n b}$ ions diffuse far beyond their first neighbors, whereas this is not the case for $\mathrm{Li}^{b}$-type ions. The results for the $x=0.3$ glass apply also to the $x=0.2$ composition, while for the higher lithium content glasses, $x=0.4$ and $x=0.5$, Li cations are almost exclusively of the $n b$ type at $T=1250 \mathrm{~K}$.

Besides the three time regimes observed generally in the $\log -\log$ MSD curves of glasses, an additional deflection of the curves has been identified in long-time (ns time range) molecular dynamics investigations in alkali silicate glasses. ${ }^{57,58}$ This change of slope has been attributed to an accelerated motion of cations due to many-particle cooperative jumps. In the present simulations we identify sporadic correlated jumps involving two cations for $x=0.5$ and $T$ 
TABLE III. Diffusion coefficient $D$ and dc conductivity $\sigma_{\mathrm{dc}}$ at $T=1250 \mathrm{~K}$ as a function of composition $x$ in $x \mathrm{Li}_{2} \mathrm{O}-(1-x) \mathrm{B}_{2} \mathrm{O}_{3}$ glasses. Lithium ions denoted by $\mathrm{Li}$ and $\mathrm{Li}^{n b}$ indicate the average lithium ions and ions in $n b$-type sites, respectively.

\begin{tabular}{cccc}
\hline \hline & $\begin{array}{c}D(\mathrm{Li}) \\
\left(10^{-5} \mathrm{~cm}^{2} / \mathrm{sec}\right)\end{array}$ & $\begin{array}{c}\sigma_{\mathrm{dc}} \\
(\mathrm{S} / \mathrm{cm})\end{array}$ & $\begin{array}{c}D\left(\mathrm{Li}^{n b}\right) \\
\left(10^{-5} \mathrm{~cm}^{2} / \mathrm{sec}\right)\end{array}$ \\
\hline 0.2 & 0.8 & 0.5 & 1.3 \\
0.3 & 1.1 & 1.27 & 1.5 \\
0.4 & 2.0 & 3.01 & 2.0 \\
0.5 & 1.9 & 3.9 & 1.9 \\
\hline \hline
\end{tabular}

$=1250 \mathrm{~K}$, but the onset of the enhanced conductivity regime was not observed.

At long times corresponding to regime III, where MSD's vary linearly with time, the diffusion coefficients $D$ of all $\mathrm{Li}$ ions and $\mathrm{Li}^{n b}$-type ions have been determined from the Einstein diffusion equation

$$
\left\langle r^{2}\right\rangle=6 D t+C,
$$

and are listed in Table III for $T=1250 \mathrm{~K}$. The diffusion coefficients that are extracted from the MSD curves of all lithium ions, $D(\mathrm{Li})$, can be used to compute the dc conductivity of glass, $\sigma_{\mathrm{dc}}$, in terms of the Nernst-Einstein relation

$$
\sigma_{\mathrm{dc}}=N q^{2} D(\mathrm{Li}) / k_{B} T,
$$

where $N$ is the number concentration of $\mathrm{Li}$ ions with charge $q(+1 e)$ and $k_{B}$ and $T$ have the usual meaning. Values of $\sigma_{\mathrm{dc}}$ at $1250 \mathrm{~K}$ are presented in Table III as a function of glass composition.

It is evident from Table III that both $D(\mathrm{Li})$ and $\sigma_{\mathrm{dc}}$ increase with lithium oxide content as observed in experiments; however, the MD results give much higher values compared to experimental measurements in the glassy state. ${ }^{59,60}$ Such differences have been observed in other simulation studies as well and can be attributed to the fact that computer-simulated glasses have higher fictive temperatures than real glasses due to either the high cooling rates involved in simulations and/or to deficiencies of the employed potential models. ${ }^{47,48,50}$ In addition, the simulations are performed at temperatures which are considerably higher than those of the experimental measurements, and this has a pronounced effect on thermally activated processes like ion diffusion. Therefore, direct comparison between ionic conductivity obtained from MD simulations and experimental measurements is not meaningful.

The increase of the total diffusion coefficient, $D(\mathrm{Li})$, with lithium oxide content can be related to the increased population of NBO-containing borate units which provide the sites for the more mobile $\mathrm{Li}^{n b}$ ions. Indeed, as illustrated in Fig. $12, D(\mathrm{Li})$ and the population of $\mathrm{Li}^{n b}$ cations exhibit very similar dependences on lithium oxide content. It is noted also that $D(\mathrm{Li})$ appears to reach saturation in the $x=0.4-0.5$ composition range, even though all lithium ions are practically of $\mathrm{Li}^{n b}$ type at such high lithium contents and temperature $(T=1250 \mathrm{~K})$. Similar effects were observed in dc conductivity measurements of Na-borate glasses, where the

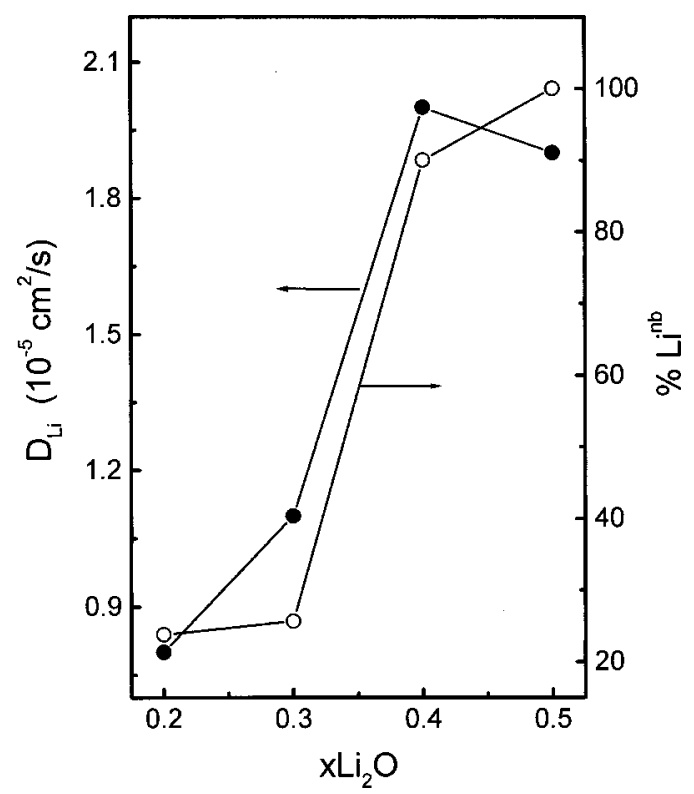

FIG. 12. Diffusion coefficients $D(\mathrm{Li})$ of lithium cations $(-)$ and percentages of $\mathrm{Li}^{n b}$ ions $(\bigcirc)$ at $T=1250 \mathrm{~K}$ as a function of composition in $x \mathrm{Li}_{2} \mathrm{O}-(1-x) \mathrm{B}_{2} \mathrm{O}_{3}$ glasses.

conductivity was found to attain its maximum value at ca. $x=0.5$ and then to decrease upon further increase of sodium ion concentration. ${ }^{61}$ In view of the importance of cooperative motions of ions observed in silicate glasses, ${ }^{57,58}$ the appearance of saturation effects in the conductivity requires further investigation.

At low lithium ion contents, i.e., $x=0.2$ and 0.3 , the main contribution in the diffusion process may originate from cation-hosting regions involving NBO's, which, however, should be relatively isolated as suggested by the small NBO (NBO) coordination numbers (Table II). With increasing $\mathrm{Li}$ ion content $(x=0.4$ and 0.5$)$ the NBO (NBO) coordination number shows an abrupt increase, and this signals the aggregation of $\mathrm{NBO} / \mathrm{Li}$-rich regions that may lead to formation of microchannels suitable for ion migration. This structural aspect is illustrated in the snapshot presented in Fig. 13 for glass $0.5 \mathrm{Li}_{2} \mathrm{O}-0.5 \mathrm{~B}_{2} \mathrm{O}_{3}$ simulated at $1250 \mathrm{~K}$. The formation of percolating Li-rich regions is shown very clearly in this figure and provides support for the applicability of the modified random network mode ${ }^{32}$ in glasses with high alkali content.

As shown above, $\mathrm{Li}^{n b}$ and $\mathrm{Li}^{b}$ cations exhibit a considerable difference in diffusivity. To address the question concerning the origin of this difference we examine the time evolution of the anionic environments hosting individual $\mathrm{Li}^{n b}$ and $\mathrm{Li}^{b}$ ions. Starting with $\mathrm{Li}$ ions of the $\mathrm{Li}^{n b}$ type, we label and keep a record of the number of NBO's that are in the vicinity of a particular $\mathrm{Li}^{n b}$ ion at time $t=0$ and count how many of those initial NBO's are revisited during the course of the simulation. Results are shown in Fig. 14 for glass composition $0.2 \mathrm{Li}_{2} \mathrm{O}-0.8 \mathrm{~B}_{2} \mathrm{O}_{3}$ simulated at $T$ $=1250 \mathrm{~K}$. Figure 14 (a) shows very clearly that after ca. 20 ps the particular $\mathrm{Li}^{n b}$ ion abandons completely its initial neighborhood and establishes a new NBO environment [Fig. 14(b)]. A similar procedure is followed for $\mathrm{Li}^{b}$ cations [Figs. 


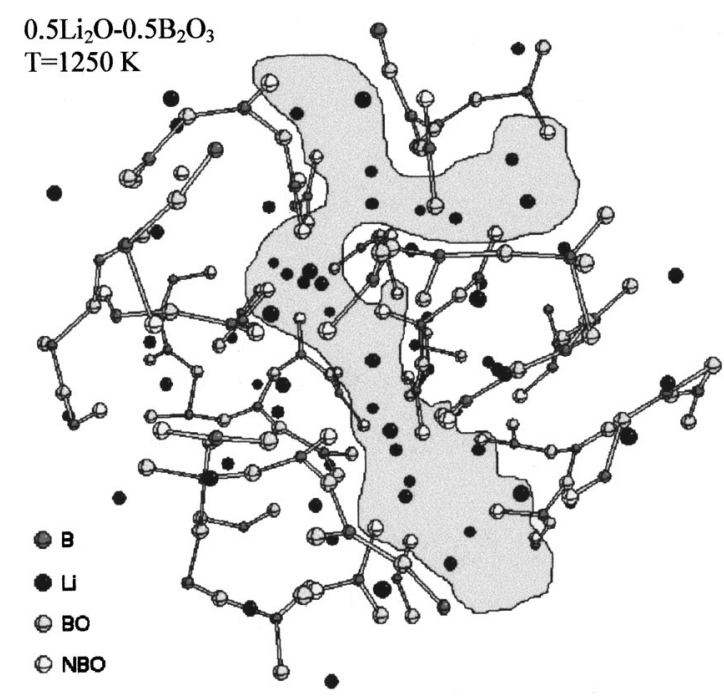

FIG. 13. Representative configuration of the atomic structure of the $0.5 \mathrm{Li}_{2} \mathrm{O}-0.5 \mathrm{~B}_{2} \mathrm{O}_{3}$ glass resulting from computer simulation of the structure at $T=1250 \mathrm{~K}$. The highlighted area shows a "microchannel" suitable for Li ion migration.

14(c) and 14(d)] where we keep a time record of the number and labels of the tetrahedrally coordinated boron atoms that contribute oxygen in the coordination sphere of a particular $\mathrm{Li}^{b}$ ion at $t=0$. In contrast to the evolution of $\mathrm{Li}^{n b}$ environment, it was found that $\mathrm{Li}^{b}$ cations tend either not to abandon their initial neighborhood entirely or to recur to it after some time [Figs. 14(c) and 14(d)]. Therefore, the higher mobility of $\mathrm{Li}^{n b}$ cations should be related to the relative ease for local rearrangements of the NBO-containing environment that promote ion hoping to neighboring sites, in comparison to the more rigid anionic environments formed by $\mathrm{B}_{4}{ }^{-}$tetrahedral units.

As noted in the Introduction, the metal-ion-site vibration frequencies in alkali borate glasses were correlated with the optical basicity of glass through a simple linear relationship. ${ }^{38}$ In this context, the sites of host metal cations responsible for bands $H$ and $L$ in the far infrared [Fig. 9(a)] were correlated with high and low basicity, respectively. This approach was found very useful to understand differences in experimental optical basicity signaled by guest probe ions, like $\mathrm{Tl}^{+}$and $\mathrm{Pb}^{2+}$. In particular, it was shown that when the probe ion is introduced in the glass from the melt it occupies sites of low and/or high basicity depending on glass composition and type of probe ion. However, when the probe ion is injected into the glass by electrolysis below $T_{g}$, then it signals sites of high basicity only. ${ }^{62,63}$ These results were taken to indicate that $H$-type sites facilitate metal ion transport more effectively than the $L$-type sites. ${ }^{38}$ The present MD results support fully this notion since the $H$ - and $L$-type sites were identified with $n b$ - and $b$-type sites, respectively, and $\mathrm{Li}^{n b}$ ions were found above to exhibit larger diffusion coefficients than $\mathrm{Li}^{b}$ ions. Very relevant to this point are also the recent findings of Yano et al. ${ }^{64}$ on $\mathrm{Ag}^{+} / \mathrm{Na}^{+}$-ion-exchanged aluminosilicate glasses. They report that when the exchange ratio is low $\mathrm{Ag}^{+}$ions are replacing first $\mathrm{Na}^{+}$ions at the NBO-containing sites. Only after full replacement at the
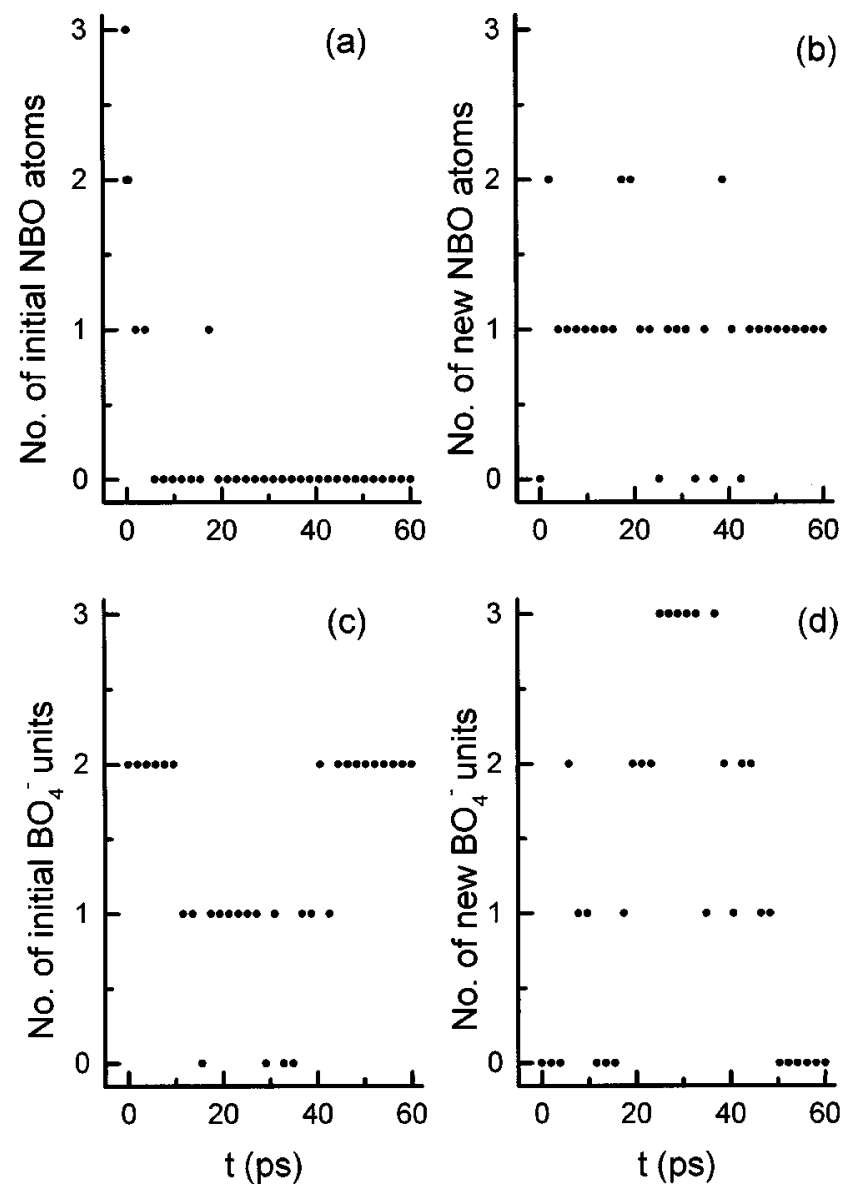

FIG. 14. Time evolution of the anionic environments hosting lithium ions in the glass $0.2 \mathrm{Li}_{2} \mathrm{O}-0.8 \mathrm{~B}_{2} \mathrm{O}_{3}$ simulated $T=1250 \mathrm{~K}$. (a) Evolution of the initial neighborhood of a particular $\mathrm{Li}^{n b}$ ion and (b) number of new NBO atoms visited in time by the same $\mathrm{Li}^{n b}$ cation. (c) Evolution of the initial neighborhood of a particular $\mathrm{Li}^{b}$ ion and (d) number of new $\mathrm{B} \emptyset_{4}{ }^{-}$units visited in time by the same $\mathrm{Li}^{b}$ ion.

NBO sites, $\mathrm{Na}^{+}$ions at $\mathrm{Al}_{4}{ }^{-}$sites start being exchanged by $\mathrm{Ag}^{+}$ions. These results strengthen further the view that different types of cation site exist in ionic glasses, with distinct dynamic characteristics of cations in the various sites as manifested in far-IR and dielectric spectra, MD results, and ion transport properties.

\section{CONCLUSIONS}

In this work, we have performed a molecular dynamics simulation of Li-borate glasses, $x \mathrm{Li}_{2} \mathrm{O}-(1-x) \mathrm{B}_{2} \mathrm{O}_{3}$, to investigate the effect of composition $(0.2 \leqslant x \leqslant 0.5)$ and temperature $(300 \mathrm{~K} \leqslant T \leqslant 1250 \mathrm{~K})$ on the short-range order structure and on the nature of the local anionic environments coordinating $\mathrm{Li}$ ions. The structure of the computersimulated glasses was discussed in relation with structural data obtained from NMR and vibrational studies, as well as with regards to transport properties of the glasses under investigation.

The SRO structure at room temperature was found to consist of triangular borate units, $\mathrm{B} \emptyset_{3}, \mathrm{~B}_{2} \mathrm{O}^{-}$, and $\mathrm{B} \emptyset \mathrm{O}_{2}{ }^{2-}$, 
and borate tetrahedral, $\mathrm{B} \emptyset_{4}{ }^{-}$, with composition-dependent molar fractions. The temperature was found to affect the relative population of the SRO units, and, in particular, the increase of temperature was shown to induce the progressive transform of $\mathrm{B}_{4}{ }^{-}$units into the charged triangles $\mathrm{B}_{2} \mathrm{O}^{-}$ and ${\mathrm{B} \emptyset \mathrm{O}_{2}}^{2-}$. These structural rearrangements were expressed by two chemical equilibria $\mathrm{B} \emptyset_{4}{ }^{-} \rightleftarrows \mathrm{B}_{2} \mathrm{O}^{-}$and ${ }^{-}$ОФВОВФО ${ }^{-} \rightleftarrows \emptyset_{2} \mathrm{BOBO}_{2}{ }^{2-}$, with both shifting to the right when temperature increases.

Detailed knowledge of the SRO structure was instrumental in distinguishing two types of cation hosting site: (a) sites formed by charged nonbridging oxygen atoms of $\mathrm{B} \emptyset_{2} \mathrm{O}^{-}$or $\mathrm{B} \emptyset \mathrm{O}_{2}^{-2}$ units and bridging oxygen atoms of neutral $\mathrm{B} \emptyset_{3}$ units ( $n b$-type sites) and (b) sites involving only $\mathrm{BO}$ atoms of charged $\mathrm{B}_{4}{ }^{-}$units and of neutral $\mathrm{B} \emptyset_{3}$ triangles (b-type sites). Thus lithium ions were labeled $\mathrm{Li}^{n b}$ and $\mathrm{Li}^{b}$ when they occupy $n b$ - and $b$-type sites, respectively. A strong preference of $\mathrm{Li}$ ions to reside in $n b$-type environments and a tendency for $\mathrm{Li} / \mathrm{NBO}$ aggregation was demonstrated at large lithium oxide contents and high temperatures. Under such conditions, evidence was provided for the percolation of $\mathrm{Li} /$ NBO-rich regions into microchannels though the glassy network, which facilitate Li ion migration in accordance with the modified random network model.

The distinction of Li cations in terms of the type of environments in which they predominantly reside was found to be paralleled by differences in the short- and long-time dynamics of lithium ions. In particular, the anharmonic short- time motions of $\mathrm{Li}^{n b}$ and $\mathrm{Li}^{b}$ cations in their local $n b$ - and $b$-type cages were found to result in two distinct responses in the far infrared, the superposition of which describes very well the experimental far-infrared profile. This finding elucidates the microscopic origin of the two component bands into which the experimental far-infrared spectra are usually deconvoluted.

Differences in long-time motions between $\mathrm{Li}^{n b}$ and $\mathrm{Li}^{b}$ ions were manifested in their mobilities, as evidenced from mean-square displacement data. It was found that $\mathrm{Li}^{n b}$ ions are characterized by higher diffusion coefficients in comparison to $\mathrm{Li}^{b}$ ions. The origin of this behavior was traced to the ability of $\mathrm{Li}^{n b}$ ions to explore different anionic environments by abandoning gradually their initial neighborhood, whereas $\mathrm{Li}^{b}$ ions were shown to navigate close to their initial site during the simulation time. In view of the present results, the nature of the cation-cation correlation effects and of the diffusion mechanisms which may characterize the different types of Li cations are currently under investigation.

\section{ACKNOWLEDGMENTS}

Partial support of this work by the Greek General Secretariat for Research and Technology (Project No. PENED9999ED44) and by the EU (Project Nos. INTAS 99-01162 and HPMD-CT-2000-00033) is gratefully acknowledged. The authors thank Dr. G. D. Chryssikos for fruitful discussions on the structure of crystalline borate compounds.
*Author to whom correspondence should be addressed. FAX: 3017273794. Electronic address: eikam@eie.gr

${ }^{1}$ C. A. Angell, Annu. Rev. Phys. Chem. 43, 693 (1992); Solid State Ionics 18\&19, 72 (1986).

${ }^{2}$ A. Bunde, K. Funke, and M. D. Ingram, Solid State Ionics 105, 1 (1998).

${ }^{3}$ T. Minami, J. Non-Cryst. Solids 95\&96, 107 (1987).

${ }^{4}$ M. D. Ingram, Curr. Opin. Solid State Mater. Sci. 2, 399 (1997).

${ }^{5}$ M. Shibata, C. Sanchez, H. Patel, S. A. Feller, J. Stark, G. Sumcad, and J. Kasper, J. Non-Cryst. Solids 85, 29 (1986).

${ }^{6}$ G. E. Jellison, S. A. Feller, and P. J. Bray, Phys. Chem. Glasses 19, 52 (1978).

${ }^{7}$ J. Zhong and P. J. Bray, J. Non-Cryst. Solids 111, 67 (1989).

${ }^{8}$ E. I. Kamitsos, M. A. Karakassides, and G. D. Chryssikos, Phys. Chem. Glasses 28, 203 (1987).

${ }^{9}$ K. Fukumi, K. Ogawa, and J. Hayakawa, J. Non-Cryst. Solids 151, 217 (1992).

${ }^{10}$ E. I. Kamitsos, A. P. Patsis, M. A. Karakassides, and G. D. Chryssikos, J. Non-Cryst. Solids 126, 52 (1990); E. I. Kamitsos, G. D. Chryssikos, A. P. Patsis, and M. A. Karakassides, ibid. 131-133, 1092 (1991).

${ }^{11}$ A. H. Verhoef and H. W. den Hartog, J. Non-Cryst. Solids 182, 221 (1995).

${ }^{12}$ L. Cervinka, F. Rocca, P. Fornasini, and G. Dalba, J. Non-Cryst. Solids 150, 140 (1992).

${ }^{13}$ J. Swenson, L. Borjesson, and W. S. Howells, Phys. Rev. B 52, 9310 (1995).

${ }^{14}$ J. Swenson, L. Borjesson, and W. S. Howells, Phys. Rev. B 57, 13514 (1998).
${ }^{15}$ H. Inoue, N. Aoki, and I. Yasni, J. Am. Ceram. Soc. 70, 622 (1987).

${ }^{16}$ W. Soppe, C. Van der Marel, and H. W. den Hartog, J. Non-Cryst. Solids 101, 101 (1988).

${ }^{17}$ A. H. Verhoef and H. W. den Hartog, J. Non-Cryst. Solids 182, 235 (1995).

${ }^{18}$ A. N. Cormack and B. Park, Phys. Chem. Glasses 41, 272 (2000).

${ }^{19}$ R. J. Araujo, J. Non-Cryst. Solids 58, 201 (1983).

${ }^{20}$ J. F. Stebbins and S. E. Ellsworth, J. Am. Ceram. Soc. 79, 2247 (1996); S. Sen, Z. Xu, and J. F. Stebbins, J. Non-Cryst. Solids 226, 29 (1998).

${ }^{21}$ C. P. Varsamis, E. I. Kamitsos, and G. D. Chryssikos, Phys. Rev. B 60, 3885 (1999).

${ }^{22}$ R. Akagi, N. Ohtori, and N. Umesaki, J. Non-Cryst. Solids 293295, 471 (2001).

${ }^{23}$ E. I. Kamitsos and G. D. Chryssikos, J. Mol. Struct. 247, 1 (1991).

${ }^{24}$ J. Krogh-Moe, Ark. Kemi 14, 1 (1959); J. Krogh-Moe, Phys. Chem. Glasses 3, 208 (1962).

${ }^{25}$ K. Kamiya, S. Sakka, T. Mizuno, and T. Matusita, Phys. Chem. Glasses 22, 1 (1981).

${ }^{26}$ E. Ratai, M. Janssen, and H. Eckert, Solid State Ionics 105, 25 (1998).

${ }^{27}$ E. I. Kamitsos, A. P. Patsis, and G. D. Chryssikos, J. Non-Cryst. Solids 152, 246 (1993).

${ }^{28}$ E. I. Kamitsos and G. D. Chryssikos, Solid State Ionics 105, 75 (1998).

${ }^{29}$ T. Uchino and T. Yoko, in Borate Glasses, Crystals and Melts, edited by A. C. Wright, S. A. Feller, and A. C. Hannon (Society 
of Glass Technology, Sheffield, UK, 1997), pp. 417-424.

${ }^{30}$ A. C. Wright, N. M. Vedishcheva, and B. A. Shakhmatin, in Borate Glasses, Crystals and Melts, edited by A. C. Wright, S. A. Feller, and A. C. Hannon (Society of Glass Technology, Sheffield, UK, 1977), pp. 80-87; J. Non-Cryst. Solids 192\&193, 92 (1995).

${ }^{31}$ M. D. Ingram, M. A. Mackenzie, W. Muller, and M. Torge, Solid State Ionics 28-30, 677 (1988).

${ }^{32}$ G. N. Greaves, J. Non-Cryst. Solids 71, 203 (1985); G. N. Greaves, Philos. Mag. B 60, 793 (1989); G. N. Greaves, and K. L. Ngai, Phys. Rev. B 52, 6358 (1995).

${ }^{33}$ P. Maas, A. Bunde, and M. D. Ingram, Phys. Rev. Lett. 68, 3064 (1992); A. Bunde, K. Funke, and M. D. Ingram, Solid State Ionics 86-88, 1311 (1996).

${ }^{34}$ R. J. Elliott, L. Perondi, and R. A. Barrio, J. Non-Cryst. Solids 168, 167 (1994).

${ }^{35}$ M. D. Ingram, J. Non-Cryst. Solids 222, 42 (1997).

${ }^{36}$ R. A. Montani, J. Non-Cryst. Solids 215, 307 (1997).

${ }^{37}$ B. H. Schulz, M. Dubiel, and M. Schulz, J. Non-Cryst. Solids 241, 149 (1998).

${ }^{38}$ E. I. Kamitsos, G. D. Chryssikos, A. P. Patsis, and J. A. Duffy, J. Non-Cryst. Solids 196, 249 (1996); J. A. Duffy, B. Harris, E. I. Kamitsos, G. D. Chryssikos, and Y. D. Yiannopoulos, J. Phys. Chem. B 101, 4188 (1997).

${ }^{39}$ G. J. Exarhos, P. J. Miller, and W. M. Risen, Solid State Commun. 17, 29 (1975); E. I. Kamitsos, M. A. Karakassides, and G. D. Chryssikos, Solid State Ionics 28-30, 687 (1988); E. I. Kamitsos, Y. D. Yiannopoulos, H. Jain, and W. C. Huang, Phys. Rev. B 54, 9775 (1996).

${ }^{40}$ S. Feller, J. Kottke, J. Welter, S. Nijhawan, R. Boekenhauer, H. Zhang, D. Feil, C. Paramswar, K. Budhwani, M. Affatigato, A. Bhatnagar, G. Bhasin, S. Bhowmik, J. Mackenzie, M. Royle, S. Kambeyanda, P. Pandikuthira, and M. Sharma, in Borate Glasses, Crystals and Melts, edited by A. C. Wright, S. A. Feller, and A. C. Hannon (Society of Glass Technology, Sheffield, UK, 1997), pp. 246.

${ }^{41}$ O. V. Mazurin and M. V. Streltsina, Handbook of Glass Data (New York, Elsevier, 1985), pt. B.

${ }^{42}$ M. P. Allen, and D. J. Tildesley, Computer Simulations of Liquids (Clarendon, Oxford, 1986), p. 156.

${ }^{43}$ W. Smith, G. N. Greaves, and M. J. Gillan, J. Chem. Phys. 103, 3091 (1995); W. Smith, G. N. Greaves and M. J. Gillan, J. Non-
Cryst. Solids 192\&193, 267 (1995).

${ }^{44}$ J. Oviedo and J. F. Sanz, Phys. Rev. B 58, 9047 (1998).

${ }^{45}$ J. Krogh-Moe, Acta Crystallogr., Sect. B: Struct. Crystallogr. Cryst. Chem. 24, 179 (1968).

${ }^{46}$ W. H. Zachariasen, Acta Crystallogr. 17, 749 (1964).

${ }^{47}$ S. Balasubramanian and K. J. Rao, J. Non-Cryst. Solids 181, 156 (1994).

${ }^{48}$ A. Karthikeyan and K. J. Rao, J. Phys. Chem. B 101, 3105 (1997).

${ }^{49}$ J. A. Kapoutsis, E. I. Kamitsos, G. D. Chryssikos, Y. D. Yiannopoulos, A. P. Patsis, and M. Prassas, in Proceedings of the International Symposium on Glass Science and Technology, edited by G. D. Chryssikos and E. I. Kamitsos (Athens, 1993); Chimica Chronica, New Ser. 23, 314 (1994).

${ }^{50}$ A. Karthikeyan, P. Vinatier, A. Levasseur, and K. J. Rao, J. Phys. Chem. B 103, 6185 (1999).

${ }^{51} \mathrm{P}$. Tarte, Spectrochim. Acta 21, 313 (1965).

${ }^{52}$ M. Gabelica-Robert and P. Tarte, Spectrochim. Acta, Part A 35, 649 (1979).

${ }^{53}$ A. Rulmont and P. Tarte, Spectrochim. Acta, Part A 49, 1696 (1993).

${ }^{54}$ S. Devautour, C. P. E. Varsamis, F. Henn, E. I. Kamitsos, J. C. Giuntini, J. V. Zanchetta, and J. Vanderschueren, J. Phys. Chem. B 105, 5657 (2001).

${ }^{55}$ D. Knodler, P. Pendzig, and W. Dietrich, Solid State Ionics 8688, 29 (1996).

${ }^{56}$ K. Funke, Prog. Solid State Chem. 22, 111 (1993).

${ }^{57}$ J. Habasaki, I. Okada, and Y. Hiwatari, Phys. Rev. B 55, 6309 (1997).

${ }^{58}$ J. Habasaki, I. Okada, and Y. Hiwatari, J. Phys. Soc. Jpn. 67, 2012 (1998).

${ }^{59}$ Y. Ito, K. Miyauchi, and T. Oi, J. Non-Cryst. Solids 57, 389 (1983).

${ }^{60}$ M. Eddrief, P. Dzwonkowski, C. Julien, and M. Balkanski, Solid State Ionics 45, 77 (1991).

${ }^{61}$ S. W. Martin, Solid State Ionics 18\&19, 472 (1986).

${ }^{62}$ F. G. K. Baucke and J. A. Duffy, J. Electrochem. Soc. 127, 2230 (1980).

${ }^{63}$ F. G. K. Baucke and J. A. Duffy, J. Chem. Soc., Faraday Trans. 1 79, 661 (1983).

${ }^{64}$ T. Yano, T. Nagano, J. Lee, S. Shibata, and M. Yamane, J. NonCryst. Solids 270, 163 (2000). 